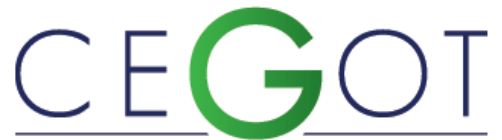

Centro de Estudos de Geografia e Ordenamento do Território
Geografia e Ordenamento do Território, Revista Eletrónica Centro de Estudos de Geografia e Ordenamento do Território http://cegot.org

Abascal, EUNICE

Universidade Presbiteriana Mackenzie, Faculdade de Arquitetura e Urbanismo, Programa de Pós-Graduação em

Arquitetura e Urbanismo

01548000 Rua Vasconcelos Drumond, 234, ap. 12 São Paulo, Brasil

Eunicehelena.abascal@mackenzie.br

BILbaO, CARLOS

FESP Fundação Escola de Sociologia e Política de São Paulo 01548000 Rua Vasconcelos Drumond, 234, ap. 12 São Paulo, Brasil eunicehab@gmail.com

\title{
Das intervenções setoriais à cidade-região: o Plano Bilbao Biscaia Next - processos, avanços e desafios
}

From the sectorial interventions to the city-region: the Bilbao Biscay Next Plan - processes, advances and challenges

Referência: Abascal, Eunice; Bilbao, Carlos (2018). Das intervenções setoriais à cidade-região: o Plano Bilbao Biscaia Next processos, avanços e desafios. Revista de Geografia e Ordenamento do Território (GOT), n. ${ }^{\circ} 14$ (setembro). Centro de Estudos de Geografia e Ordenamento do Território, p. 5-46, dx.doi.org/10.17127/got/2018.14.001

\section{RESUMO}

O Plano Bilbao Biscaia Next, ou Bilbao 45, para os municípios da região metropolitana de Bilbao e outros, distantes até 45 minutos da capital biscaina, considerados chave à especialização inteligente, é uma proposta multiescalar e um Plano Estratégico de desenvolvimento urbano e regional, articulado a Projetos Urbanos Estratégicos. A evolução metodológica, conceitual e prática da recuperação urbana de Bilbao, de 2001 a 2017 revela uma busca em superar a visão dos Projetos Urbanos como intervenção setorial, em direção de intervenções multiescalares e policêntricas, integrando-se a projetos urbanos e a um planejamento socioeconômico e territorial. O artigo expõe as razões e características do Plano, apresenta seus objetivos e métodos, e sinaliza potencialidades e fragilidades, identificando desafios de implementação, a despeito da concepção policêntrica e reticular que o motivam.

Palavras-chave: cidade-região; Bilbao Biscaia Next; Projeto Urbano Estratégico; redes; policentrismo.

\section{ABSTRACT}

The Bilbao Biscay Next Plan, or Bilbao 45, for municipalities in the metropolitan region of Bilbao and others, as far as 45 minutes from the capital city of Bizkaia, considered a key to intelligent specialization, is a multi-scale proposal and a Strategic Plan for urban and regional development articulated to Strategic Urban Projects. The methodological, conceptual and practical evolution of Bilbao's urban recovery from 2001 to 2017 reveals a quest to overcome the vision of Urban Projects as a sector intervention, towards multiscalar and polycentric interventions, integrating urban projects and socioeconomic planning and territorial. The article sets out the reasons and characteristics of the Plan, presents its 
objectives and methods, and indicates potentialities and weaknesses, identifying implementation challenges, despite the polycentric and reticular conceptions that motivate it.

Keywords: city-region; Bilbao Biscay Next; Strategic Urban Project; networks; polycentrism

\section{Introdução}

A par do reconhecido sucesso da regeneração urbana de Bilbao (Espanha), que se estende desde o início da década de 2000 até os dias de hoje, há que se dizer que há muitos "Bilbaos", o que se evidencia pelo papel de unidade funcional que a Grande Bilbao, a área metropolitana dotada de 35 municípios, confere à região. Se a cidade revelou a partir de então sua vocação de serviços, foi na Grande Bilbao em que se deu a pujança industrial que Ihe fez história. Presente nos vários municípios ao longo do Rio Nervión, relacionados econômica e culturalmente a outras regiões do País Basco (Euskadi), a localização das indústrias foi facultada por um complexo sistema intermodal de infraestrutura de mobilidade. Esse território e processo parecem aguardar ainda por uma transformação que transcenda tão somente a soma de boas realizações: o Museu Guggenheim (inaugurado em 1998), o projeto do Metrô de Norman Foster (1995), estradas e ferrovias, alcançando verdadeiramente uma transformação metropolitana e regional. Esse desafio se impõe hoje às autoridades governamentais e à sociedade, a fim de resgatar uma visão metropolitana e regional que os planos parecem não levar adiante com a necessária força e profundidade (CENICACELAYA, 2004).

Ao longo dos anos de 1980, quando a cidade demonstrou sua inclinação ao urbanismo requalificador, faltavam ainda uma visão e instrumentos para alcançar uma transformação propriamente metropolitana, que se desenvolvia por meio das muitas realizações infraestruturais, algumas emblemáticas, obras públicas e boas estradas, e diversos modais de transporte. É possível afirmar que o metrô foi a mais significativa obra, por deflagrar uma visão metropolitana de planejamento, mas o futuro parece apontar, para além do urbanismo e da infraestrutura, para a necessidade de mecanismos de equilíbrio dos efeitos da especulação imobiliária e valorização do solo produzidos pela requalificação urbana, que surgem simultaneamente à positiva geração de empregos qualificados e especialização produtiva. 
O Plano Bilbao Biscaia Next (Bilbao 45) vem sendo elaborado desde 2013, tendo o município de Bilbao como epicentro, e inclui os municípios de sua região metropolitana e alguns outros, localizados não somente na província de Biscaia, distantes no entanto, até 45 minutos da capital biscaina. Considera os municípios que o integram meios para a especialização inteligente, escolhas racionais por meio de um processo colaborativo, que envolve o maior número de interessados, em especial, centros de investigação, empresas líderes e empresários (URBACT, 2018). Fundamenta-se em estudos baseados em uma pesquisa-ação, que tem por objetivo induzir vantagens competitivas mediante o conhecimento dos pontos fortes, fracos e oportunidades territoriais. É uma proposta multiescalar e um Plano Estratégico de desenvolvimento urbano e regional, articulado a Projetos Urbanos Estratégicos (VEGARA; RIVAS, 2004), distribuídos nos vários municípios em tese articulados em rede. Trata-se de uma aposta num futuro em que o território possa ser planejado sinergica e integradamente. Num raio incluido no âmbito da integração das três maiores capitalidades do País Basco - Bilbao, Donostia (San Sebastián) e Vitoria, também relativamente próximas umas das outras e bem conectadas entre si, o Plano pretende integrar Bilbao a municípios estratégicos que integram a região metropolitana e a outros próximos, localizados até mesmo em outras províncias, que podem manter relações de interesse socioeconômico com a Grande Bilbao. Uma nova estação do Trem de Alta Velocidade (TAV) está prevista para integrar San Sebastián e Vitoria em 2018, amplificando a conectividade regional.

A evolução metodológica, conceitual e prática da recuperação urbana de Bilbao, de 2001 a 2017, que culmina no Plano Bilbao Biscaia Next, revela uma procura por superar a visão que motivou Projetos Urbanos e intervenções meramente setoriais, rumo a opções multiescalares e policêntricas, de que é exemplo o Plano em questão, integrado a um planejamento socioeconômico e territorial sob gestão das atuais políticas da União Europeia que dirimem sobre as cidades, em perspectiva local, regional e global.

Este artigo expõe as razões e características do Plano Bilbao Biscaia Next, apresenta seus objetivos e métodos, e sinaliza potencialidades e fragilidades, fundamentando-se em indicadores socioeconômicos do território-alvo que indicam avanços e desequilíbrios, decorrentes da especialização produtiva acarretada pela inovação e requalificação urbana. No âmbito regional e sub-regional, fluxos populacionais intermunicipais e diferenças de 
renda per capita e de oportunidades de trabalho especializado podem ser verificados, indicando a produção de diferenças e desequilíbrios. Comparam-se estes índices e o que significam em termos de fluxos socioeconômicos às propostas de uma espacialização policêntrica e sinérgica sugerida entre os diversos municípios abrangidos pelo Plano, identificando desafios para a implementação da especialização inteligente em nível regional, a despeito das positivas contribuições de uma concepção reticular que o motivam. A transformação induzida proposta tem como capitalidade e área de influência principal a cidade de Bilbao, que iniciou seu processo de recuperação mundialmente conhecido pelo papel de promoção cultural do Museu Guggenheim, na década de 1990, e que se estende até os dias atuais. Apresenta-se o modelo de desenvolvimento que hoje se entende como capaz de produzir um equilíbrio entre os municípios que integram o Plano Bilbao Biscaia Next, e os instrumentos utilizados para um planejamento regional sistêmico, que inclua uma rede policêntrica de municípios, em tese cooperativos. O modelo de intervenção e planejamento sugerido pelo Plano se baseia na compreensão de que os municípios são parte de um todo, ao qual Projetos Urbanos se conectam, logística, social, e economicamente ao território municipal e regional, integrando "Projetos Urbanos Estratégicos" (VEGARA; RIVAS, 2004).

A concepção de Bibao 45, iniciada em 2013, enfatiza a coesão entre plano e projeto para alcançar a cidade-região, caracterizada por uma extensão definida a partir de relações entre municípios que exercem influências mútuas, potencializadas por sistemas de conexão policentrais (INDOVINA, 2002). A policentralidade, como expressão física de redes globais e locais, é concebida como um meio para o desenvolvimento proativo das cidades envolvidas, inserindo seus possíveis Projetos Urbanos em múltiplas escalas, que estão enunciadas no plano Bilbao Biscaia Next.

\section{Espaço, escala e sociedade - cidade-região como locus privilegiado para uma economia política em rede}

A superação da ideia de que a realidade define o espaço, mas que ao contrário, de que a criação deste como opção planejada, representada como linguagem e definindo uma escala, pode transformar a realidade, está no âmago do debate sobre a transformação induzida do 
território. Soja (1993) reflete sobre a necessidade de questionar o receio da teoria crítica em fetichizar o espaço, e propõe uma inexorável aproximação ao debate da questão espacial, necessária à produção do tempo (ABASCAL; BILBAO, 2012).

Os Projetos Urbanos, passíveis de múltiplas conexões escalares, abrangem vínculos tangíveis e intangíveis (GORZ, 2005) com os territórios com os quais estão correlacionados, na condição de instrumentos de produção de escalas de transformação urbana.

Ao comentar as especificidades contemporâneas da produção do espaço, Soja (ibid.) assinala a importância do urbano, de uma problemática "imperativa" que aponta para a relevância política da cidade, como lugar privilegiado para a condução das atividades socioeconômicas no território: da mesma forma que não é a urbanização que produz a escala, mas esta pode definir a primeira, assim é possível que não seja a "industrialização" que determine o seu espaço, mas que uma ação indutora possa contribuir para a configuração do território e reorganizar a atividade da indústria. É possível dizer que sob essa ótica, a produção depende de seu espaço, e o processo de acumulação é dependente da produção social do território. A definição de extensões e fronteiras urbano-regionais se converteria assim em um instrumento "estratégico", por meio do qual se poderia induzir a fixação e os fluxos de populações no espaço intra e extra urbano, definindo assim a regionalização como um processo de mediação da circulação do capital, com efeitos internos - regionais e globais (op. Cit.).

Saskia Sassen (2007) pondera como as cidades podem contribuir hoje mais para o mundo globalizado do que o fizeram sob a perspectiva keynesiana de até meados dos anos 90, e de como a especialização produtiva, característica das regiões, pode ao mesmo tempo suprir o mercado global e interno. O espaço urbano é em si mesmo um fator de produção para a realização de circuitos regionais e globais, explicando particularmente porque a arquitetura, o desenho urbano e o planejamento urbano e regional desempenham papel central nesse processo. Sassen (2007) enfatiza que não existe uma entidade tal como "a" economia global, mas uma rede vasta que multiplica circuitos (redes), que, ao mesmo tempo em que cruzam o globo, especializam-se. Os vários circuitos incluem grupos, países e cidades, e o desafio urbano é estabelecer a qual circuito global e regional uma cidade pertence, e que outras cidades compartem com ela em cada um deles. O estabelecimento de redes em escala urbana e regional é assim o modo concreto - territorial - de se incluir em redes 
globais, e redes de redes: "My argument is that these emergent inter-city geographies begin to function as an infrastructure for globalisation. And they increasingly urbanise global networks" (2007, s.p). Tais geografias interurbanas passam a desempenhar o papel de infraestrutura para a globalização, e por consequência, urbanizam cada vez mais redes globais. Espaços urbanos, metropolitanos e regionais específicos, por sua vez, procuram se tornar concentrações de novas capacidades técnicas e especialização produtiva. Além disso, edifícios constituem lugares para a multiplicação de tecnologias interativas e computação distribuída, viabilizando-se em parques tecnológicos. Infraestruturas de comunicação global conectam edifícios em todo o mundo, produzindo uma geografia interativa altamente especializada (SASSEN, 2007). Espaços de centralidade globalmente interligados são como "plataformas para operações globais de empresas e mercados" (id., ibid. s. p.), e se pode pensar como redes o conjunto conectado de partes destas (empresas, serviços), que integram uma determinada cidade-região. Tais redes integram um espaço geográfico transnacional e regional ao mesmo tempo, um "amálgama de espaços geográficos subnacionais específicos, mas também de espaços eletrônicos transnacionais" (id., ibid, s.p.). O que leva a argumentar que a especialização produtiva dos lugares é hoje um fundamento para que cidades e regiões, ou ainda, cidades-regiões - superando a dicotomia, possam se incluir na economia globalizada, o que contraria que a globalização homogeneize as economias. A especificidade importa e pode variar, dependendo da economia de uma região. A globalização homogeneiza padrões e modelos de gestão, mas precisa de capacidades econômicas especializadas.

O conhecimento de como uma cidade-região pode se tornar uma economia do conhecimento é um árduo processo, que envolve as instituições, no sentido de compreender seu território, e de reconhecer suas capacidades e potencialidades de maneira detalhada. O passado pode parecer à primeira vista um entrave para que se alcance outro patamar de inclusão em circuitos econômicos, a exemplo de Chicago, e de suas vantagens competitivas. A complexidade, a escala e o caráter internacional alcançados historicamente pela economia agroindustrial de Chicago levaram-na a uma especialização financeira, contábil e legal altamente especializada, que a pôs na direção da economia do conhecimento. No entanto, a despeito das possibilidades das regiões, estas apresentam desigualdades e desequilíbrios produtivos, fluxos populacionais e desenvolvimento, 
expressos nas diferenças entre os vários municípios que as integram, consistindo essas disparidades no desafio concreto do planejamento, pois a materialidade dos territórios que integram as redes é um cenário complexo, que inclui a promoção da qualidade de vida e do desenvolvimento equânimes.

A circulação econômica primária (industrial) e secundária (financeira), indissociáveis, são relevantes para a economia urbana, e embora a indústria ainda seja uma atividade primaz, intensifica-se a circulação financeira, especialmente nos mercados fundiário e imobiliário (SOJA, 1993). A circulação econômica secundária se realiza eminentemente no território urbanizado, materializando-se na obtenção da renda urbana, e na determinação do valor da terra, e sobre a ação de planejar, eminentemente pública, requerendo formas de regulação e a interveniência do estado, em várias escalas. Assim, se a indústria e suas atividades se redefinem, sem desaparecer, é certo que se verifica uma produção cada vez mais intensa da renda da terra no circuito secundário, exigindo uma regulação da produção do espaço urbano. O capital em circulação não só ocupa o espaço, mas o cria, para atender ao movimento de produção de valor. A definição de escalas como prática social se torna então um instrumento, uma escolha da economia política, que visa manter ou ampliar a intensidade e a extensão espaciais e dos fluxos, humanos e econômicos, a fim de reestruturá-los ou transformá-los (id., ibid.). Assim, quando se decidiu por estender o planejamento de Bilbao à sua região metropolitana, já nos anos 2000 (ABASCAL, 2004), havia uma tônica expressa no Plano Estratégico para desenvolver social e economicamente esse território, propondo-se a superar a transformação da antiga área portuária de Abandoibarra, o perímetro definido como a "joia da coroa", em que se localiza o Museu Guggenheim, por meio de um Plano Metropolitano (id., ibid.).

O planejamento, como prática de Estado, visa dirigir o desenvolvimento e a economia, e se torna em tese o meio técnico-político que contraria a "mão invisível" do mercado. Essa nova economia política afeta a uma sociedade multiconectada ou em rede, e somente pode funcionar no espaço urbanizado, igualmente multiconectado e policêntrico (PASCUAL, 2017)

Sob essa ênfase, cidade e região definem o entorno para que empresas e serviços atuem e se intensifiquem. Políticas públicas de qualificação do complexo de fatores de uma "[...] localização produtiva" (id., ibid., p. 211), são imprescindíveis para a criação das condições de funcionamento dos mercados, a partir de um Estado voltado à mitigação de desigualdades e 
promoção da governança participativa. Se essa economia política se expressa e depende do espaço, depende também diretamente da qualidade do urbano, das infraestruturas e serviços, da mobilidade e acessibilidade aos espaços públicos, e, sobretudo, de uma interconectividade interurbana, metropolitana e intermetropolitana (PASCUAL, 2017).

Do planejamento inter e multiescalar dependeria a própria inovação produtiva, como parte de um contínuo movimento induzido de interação entre os atores da economia; o ambiente urbano e metropolitano poderia gerar essa interação em rede, discurso que se encontra no fundamento do Plano Bilbao Biscaia Next, enunciando que tal prática transcenderia a realização de obras emblemáticas como seu principal mote, o que integrou um momento do planejamento próprio à emergência neoliberal dos anos de 1990.

A promoção de serviços avançados, uma condição para a especialização flexível e qualificação produtiva (PASCUAL, 2017) necessita do espaço urbano qualificado, tornandose fatores interdependentes a mobilidade, a acessibilidade e infraestruturas, e o capital simbólico (BOURDIEU, 2005) proporcionado pela arquitetura, que segue sendo uma das variáveis imprescindíveis desse processo, mas não a única.

O desenvolvimento das regiões se faz de forma desigual, notando-se o declínio de várias delas, originalmente prósperas, pela concentração ou atividade industrial primaz, com desativação de setores industriais até então vigorosos. Uma rápida industrialização de periferias regionais, bordas e fronteiras, que antes não se configuravam por meio da localização da indústria, torna-se cada vez mais frequente. A questão regional toma posição de destaque, bem como a formação de economias regionais. Assim, redes, fluxos e conectividade se tornam questões espaciais e econômico-sociais exaltadas pela teoria; e a reestruturação de sistemas de conexão um passo central para a reprodução da economia capitalista. Masboungi e Mangin (2009) ponderam, no entanto, que o Urbanismo, seja qual for o escopo de intervenção, vê-se envolvido em todas as escalas, levando em conta as realidades contextuais e específicas de cada território. Pensar os territórios como lugares de projeto, a fim de Ihes conferir atributos vitais, de paisagem, e funcionalidade urbana, incluindo aqui sua conectividade e atividades, é então o objetivo do urbanismo que se impõe um papel articulado a planos de abrangência regional. Um urbanismo de grandes territórios implica em complexas relações, tempo-espaciais entre plano e projeto, relações entre a escala macro e intervenções pontuais (MASBOUNGI; MANGIN, 2009), em diálogos 
de ação conjunta. Ao mencionar Nuno Portas, esses autores assinalam que transformar um território vasto, como uma região, requer pensar microterritórios dentro do macro, implicando que a partir das potencialidades das realidades locais, estratégias para a globalidade do território devam ser apresentadas. Ao invés de uma "grande escala", mais preciso seria pensar em escalas variáveis, desempenhando-se junto a elementos tais que obedeçam a várias lógicas de intervenção - desde a conectividade regional, o TGV, por exemplo, até a habitação. Para isso, é urgente uma visão espacial que supere a abstração da política territorial, mas uma espacialização que é bem mais que que a simples expansão de um território planejado - espaços em que as atividades e a materialidade contribuam para definir projetos-chave, tanto nos municípios como polos primazes, como nas bordas e periferia; portanto, a policentralidade é uma ação que visa distribuir atividades e fluxos de modo equilibrado, sem acentuar mais um lugar do que o outro.

Grandes territórios se integram a uma demanda global de valorização e intervenção nas periferias urbanas, a fim de incorporá-las aos fluxos locais e globais. Planejar é também decidir sobre o modo de organização que confere sentido e forma aos territórios. Esta abordagem propõe meios para enfrentar as diversas escalas territoriais.

Uma cidade-território se estende, e compreende formas diversas. Pode parecer invisível, somente presente para os profissionais que intervêm no território, e parece invisível também ao usuário, que não Ihe confere qualquer identidade particular. Requer, para ser abordada, um diagnóstico dito "não-complascente", identificando-lhe pontos fortes e desvantagens (MASBOUNGI; MANGIN, 2009), para antecipar sua constituição, dotando-a de atributos que dão suporte à sua realidade física, geográfica, humana e institucional.

A cidade reconhecida em seu sistema e suas formas de dependência em rede é bem mais que difusa, fragmentada, dispersa, emergente ou suburbana, exigindo um conjunto de intervenções capazes de melhor agenciar espaços de especialização produtiva interconectados. Esta cidade em vias de constituição, cidade nas bordas da cidade, não é uma periferia, mas existe da mesma maneira entre as cidades, formando novas centralidades em torno de eixos e formações espaciais diversas, comerciais, industriais, pequenos nós centrais, e como afirmou Bernardo Secchi (2006), já é tempo de o Urbanismo reconhecer suas responsabilidades e possibilidades transformadoras, diante de novos contextos urbanos. A sedimentação histórico-cultural das cidades compreende tecidos 
consolidados, mas processos cristalizados se opõem à rapidez das transformações infra estruturais e mudanças econômicas, mesmo se o discurso dominante se inclina hoje ao desenvolvimento sustentável, pois o território urbanizado é o lugar de exercício do mercado imobiliário e de terras.

No entanto, a organização de um espaço regional se relaciona à concentração de atividades, em torno de múltiplos centros conectados, cuja conformação é capaz de vencer a distância física. Patrick Giddens (apud SOJA, 1993) define a "modalidade dos locais", e a inexorável necessidade de superar a polaridade centro e periferia, e de uma possibilidade distributiva e regulamentadora de uma certa regionalização extensiva: o quão é necessário que a aglomeração humana se estenda no tempo e no espaço, a fim de formar múltiplos e diferenciados cenários de atuação.

Desse ponto de vista, urbanização e desenvolvimento integram o urbano a outras escalas, podendo alcançar sua máxima eficiência com a diferenciação regional. O urbano, de uma perspectiva regional, caracteriza-se pela diversidade, reunindo espaço-tempo e poder. Envolve espaços concebidos como um sistema de relações - daí o entendimento da requalificação urbana e metropolitana - tal como vivida por Bilbao nas últimas duas décadas - como a elaboração não somente de uma estratégia, mas de táticas do habitar (FOUCAULT, apud SOJA, 1993), ou de uma geografia em que âmbitos espaciais distintos - recortes escalares,- são definidos como fronteiras cuja delimitação é propriamente questão de Estado, na ação planificadora.

Essa geografia multiescalar é a base de um pensamento sistêmico, cujo domínio é o princípio da reestruturação das cidades, em integração com outros domínios escalares necessários a uma economia diversificada SOJA (1993) encontra ecos disto na teoria de Mandel, para quem o capitalismo contemporâneo demanda sistemas geograficamente hierarquizados de produção e produtividade, na sobreposição de formas distintas de produção e acumulação, o capitalismo monopolista do século XX que convive com novas rendas provenientes das tecnologias e da tecnologia da informação.

Essa mudança foi acompanhada de uma reorganização das relações de trabalho, e da supervalorização das atividades de maior valor agregado, originadas de processos sistêmicos de capacitação do capital humano (GLAESER, 2005). Para tanto, o surgimento de 
espaços que possibilitam fluxos econômicos de escalas regional e global, no setor de serviços e serviços avançados se tornou o mote para a criação de planos e projetos urbanos.

\section{O que está em jogo no desenvolvimento territorial na União Europeia - Uma nova percepção para Bilbao}

\subsection{Policentralidade e Redes como método}

A questão do planejamento do território nos países membros da União Europeia caracteriza-se hoje por um tenso jogo de lideranças, captação e gestão de recursos financeiros. Múltiplos atores e instituições intermediam a formação de redes e parcerias, tendo em vista a dotação de fundos e recursos estruturais destinados aos âmbitos regional e urbano (CONTI, 2007). O Conselho Europeu desempenha um relevante papel gestor desse processo, ao definir políticas territoriais que tenham nas cidades e em suas relações sinérgicas o principal tema e como exigência o estabelecimento de redes cooperativas de cidades, fundamentadas na ação intergovernamental. A política europeia aborda o desenvolvimento urbano a partir de uma perspectiva de redes urbanas e regionais multiescalares, em atitude pro-ativa, sinérgica e cooperativa.

A Perspectiva do Desenvolvimento Espacial Europeu (PDEE) foi concebida como um processo de longa duração, tendo se iniciado na década de 1990. Dirimiu sobre os grandes rasgos e princípios que passaram a reger a transformação do território: coesão social e econômica, desenvolvimento sustentável e planejamento para uma melhor competitividade dos lugares. Sua missão foi estabelecer os princípios para alcançar uma estratégia integrada de políticas territoriais compartilhadas em níveis diversos.

A esfera tática dessa política territorial foi definida de modo a promover relações urbanoregionais equilibradas, por meio da oferta de oportunidades laborais e de negócios, serviços, infraestrutura física e digital, e equipamentos. No que tange à espacialidade, o sistema policêntrico foi consagrado como método, e a integração de múltiplas centralidades entendida como garantia para um um novo viés para as relações das cidades e seu entorno regional, prevendo um necessário equilíbrio ao acesso à infraestrutura logística, de mobilidade e conhecimento, bem como incluindo a herança do ambiente natural e cultural (CONTI, 2007). A grande complexidade dessa integração, e as diferenças e desequilíbrios 
regionais e entre os diversos municípios consistem, no entanto, no desafio à implementação e à prática dessa política. Sinalizam que o sistema reticular proposto não é de fácil realização e desenvolvimento induzido, pois enquanto a ideia de rede suscita desconsiderar hierarquias entre seus diversos pontos ou nós, a própria conscientização da busca por uma equidade de oportunidades revela um tecido socioeconômico e produtivo desigual presente na esfera empírica, indicando situações socioespaciais distintas entre as várias centralidades, carecendo de uma análise relacional e sistêmica, a fim de que a reversão de tais processos possa ser enfrentada.

A noção de rede deve ser então problematizada em sua imanência, e para além de significar a perscrutação de formas de organização e conexão entre atores e partes (EGLER, 2012), em uma acepção puramente estrutural, no âmbito da política e da transformação induzida do território, as diferenças e os desequilíbrios, bem como as especificidades e fragilidades dessas partes - os municípios na região - deveria nortear a proposição de Planos e de projetos.

A dimensão territorial e multiescalar do desenvolvimento e da competividade traduziu um ponto de inflexão para as políticas públicas de desenvolvimento urbano-regional, passando da competição direta a outra indireta, em que se admite contar com recursos específicos disponíveis ou a ampliar nas regiões-alvo, tornando o território protagonista do desenvolvimento. Para lograr êxito, a competição indireta requer governança em torno de estratégias compartilhadas que dão suporte às empresas, mas exigem que vantagens competitivas sejam ofertadas a partir das próprias condições locais, amplificando o desafio prático. Em um exemplo destas afirmações, coloca-se a questão central de esclarecer o que planos e projetos ao nível municipal têm a contribuir ou fragilizar tais redes que se pretendem solidárias e cooperativas, no âmbito das regiões. No caso da cidade de Bilbao, epicentro do Plano Bilbao 45, esse município está desenvolvendo o que vem sendo anunciado como seu "último grande projeto urbano" - um parque tecnológico urbano e multifuncional, localizado na área de Zorrotzaurre (Deusto), para aprimorar sua especialização produtiva atual mais evidente, a produção de softwares e serviços no setor terciário avançado (LANBIDE TEKANIKA, 2018). Uma das questões críticas é compreender, até que ponto intervenções como essa, ao nível local, interferem sistemicamente em outros municípios da rede, sabendo-se, por exemplo, que em Zamudio, município próximo da 
Grande Bilbao, já está instalado outro Parque Tecnológico, desde a década de 2000. Tratase de comprender se o sucesso de Bilbao é parte de uma ação solidária para a região, ou se pode aprofundar seus desequilíbrios, deixando de constituir de fato um "Projeto Urbano Estratégico", restando a pergunta "estratégico para o que, e para quem $\dot{c}$ ". As experiências de planejamento suscitam a questão de que deveriam ir além de implementar improváveis novas vocações ao território, mas investir em tecnologias social, cultural e historicamente presentes, valorizando o que se sabe fazer e o que já se encontra disponível no território, contribuindo para de fato ampliar as competências urbanas e regionais. Uma das estratégias fundamentais para alcançar esse cenário é a integração (aglomeração) de oportunidades, em sistemas e processos produtivos, integrando-os em redes que se baseiam na colocalização de atividades complementares a uma agenda estabelecida, para estimular a cooperação dos agentes econômicos e sociais, e uma agenda compartilhada (id., ibid.), gerida por instituições sólidas com potencial intervencionista.

Alcançar estes objetivos requer o reconhecimento e a caracterização do território em profundidade, em todos os seus elementos e dimensões - cultural, histórica e natural, social econômica e de política pública, e o conhecimento e aplicação de marcos regulatórios, que merecem revisões contínuas, a fim de adaptarem-se a uma nova visão cooperativa e regional. Planos e projetos ocupam lugar central nesse processo, não como peças estanques ou soluções setoriais, mas como mediação para a concepção de lugares aonde se deseja atuar, nos quais se verificam transformações, processos materiais e relações de poder, fundamentando essa forma de planejamento, e indicando que dependem do debate público. Essa nova marcha dos planos e projetos revela-se como uma construção em processo, cuja imbricação das políticas econômicas e do planejamento territorial se faz central, encontrando um espaço em comum nas políticas de produção espacial. A matéria do desenvolvimento local não afeta apenas o território físico, mas um conjunto de bens e valores intangíveis, e a definição das dimensões social, cultural, ambiental e institucional, aptas a enfrentar juntas processos competitivos e de inovação.

O conceito de policentrismo, método proposto para alcançar os objetivos de políticas de inovação, admite três perspectivas teóricas, podendo ser considerado um processo espontâneo, um modelo teórico ou ainda, um objetivo político (CONTI, 2007). Na atualidade, é possível dizer que várias estruturas monocêntricas polarizadas se apresentam, 
mediante capitalidades dominantes, situação em tese reversível ao se intentar promover uma organização em redes. Esta nova estruturação - esta ideia de não-hierarquia das redes e de suas partes, os municípios - se opõe à dominação de um lugar frente aos demais, fazendo com que a tônica recaia nas relações de integração, interdependência e solidariedade das cidades. Em sua acepção política, o papel do policentrismo é induzir oportunidades e ofertas sócio-econômicas equilibradamente distribuídas. Tais objetivos integram desde a década de noventa do século findo as metas das políticas territoriais da Comissão Europeia.

As formas pelas quais o policentrismo como método se expressa espacialmente incluem eixos de desenvolvimento em regiões periféricas relativamente a municípios primazes, bastante desenvolvidas por formas diversas de especialização produtiva, ou ainda, deprimidas ou desertificadas devido ao êxodo e à emigração, distribuindo, reforçando ou fragilizando concentrações urbanas, cujos desequilíbrios convidam à formação de redes equipotenciais de centros competitivos, como Bilbao Biscaia Next visa estabelecer na região metropolitana de Bilbao e municípios do entorno. O policentrismo, sob esta perspectiva, é entendido como um instrumento indutor da competitividade regional e global, pois a formação de redes regionais e de cidades, no âmbito escalar da União Europeia, prevê um sistema de redes de redes, que vem sendo compreendido como articulação de alianças que podem transformar o modelo centro-periferia, que afeta ainda regiões menos favorecidas da Europa. Tais redes podem gerar compartilhamento de mão-de-obra e do mercado laboral, favorecida por infra-estrutura de mobilidade, tal como auto-estradas, aeroportos e oferta de serviços altamente especializados, que incluem a sociedade do conhecimento, a educação, saúde, profissões liberais diversas, e que agregam a contribuição social das Universidades. Ao mesmo tempo em que cada cidade deve seguir ofertando atividades tradicionais em que já é especialista, a interação em rede produz importantes ações colaborativas e de governança, e o benefício da distribuição de recursos comuns e participação em programas de viabilidade de planos e projetos.

Na UE, a coesão econômica e social, presente no Tratado de Amsterdã de 1997 (CONTI, 2007) surge como possível instrumento de regulação de conflitos entre múltiplos atores, compreendido como uma regulação das relações entre Estado e mercado. Essa política visa criar competitividade e ampliar o emprego, reparando eventuais danos causados por ações 
predatórias dos mercados ou declínio de atividades historicamente consolidadas, como a industrialização. A transformação desejada abrange três subsistemas, econômico, social e ambiental-paisagístico, postulando formas de cooperação institucional horizontal e vertical, no intuito de corrigir desequilíbrios. Uma das questões críticas centrais é que o conceito de coesão territorial (econômica e social) se propõe como antídoto aos expressivos desequilíbrios multidimensionais que se distribuem entre esses sub-sistemas. No que diz respeito à economia, a transformação urbana promovida por processos de requalificação gera elevação do valor do solo, incidindo seus efeitos nos territórios requalificados (HARVEY, 2013). O sobrevalor da terra urbana acarreta muitas vezes em processos gentrificadores, entendendo-os como movimentos de êxodo populacional motivados pelo preço da terra, e produção do espaço de forma desigual (SMITH, 1988), movimentos que aprofundam desigualdades, exigindo desse processo policêntrico e reticular uma ação contínua de reversão de efeitos perversos, desafiando as possibilidades reais de gestões técnicas e de planejadores, o que impõe um questionamento às possibilidades de implementação dos desígnios dos Planos.

Deslocamentos populacionais motivados por fragilidades de produção e geração de renda podem acarretar evasão populacional, em busca de localizações mais acessíveis, e em dispersão populacional, em busca de vantagens e oportunidades, tais como solo mais barato e empregos. A transformação do perfil socioeconômico de muitas regiões e municípios, e o impacto de outras, gera os desequilíbrios na provisão de serviços e empregos, e sobrecarga de lugares despreparados para acolher fluxos emigratórios. Novos residentes sobrecarregam os serviços e equipamentos, e o uso do automóvel e do transporte coletivo compensa a distância até centros urbanos onde há emprego e trabalho, tratando-se de percursos factíveis devido às distâncias entre 30 e 50 km. Bilbao Biscaia Next ou Bilbao 45 tem a intenção de abranger o território dos municípios bem conectados que distam até 45 minutos da capital biscaina, e planejar uma equilibrada distribuição de especializações produtivas, serviços e população.

A reconversão da área portuária de Bilbao (nas décadas de 90 e 2000) e a expressiva transformação urbana e sucesso alcançados hoje por intervenções emblemáticas requalificadoras são confrontadas com outros municípios da região metropolitana e entorno imediato, muitas vezes esvaziados ou em declínio, como tambem municípios com alta renda 
per capita e concentração de empregos, próximos da capital biscaina, e a ela interligados por sistemas de transporte consolidados e eficientes (ferrovia e metrô com alcance metropolitano, e um eficiente sistema rodoviário). A situação atravessada demonstra que a transformação das capitais, embora indispensável, não exclui a de outros territórios em sua área de influência, que se demonstram muitas vezes "cidades dormitório" ou, ao contrário, que concentram riquezas e oportunidades. Municípios requalificados podem apresentar contingente populacional que em muitos casos nem sempre trabalha onde reside, opondose a outros que se tornaram lugar de residência de imigrantes por excelência, caracterizando desequilíbrios de valor do solo, renda, oferta de empregos e geração de riquezas, com expressivos problemas e fragilidades sociais, econômicas e ambientais, ou que são polos de atração, por sua alta renda e especialização produtiva.

Essa desiguldade socioespacial incide sobre os sistemas de mobilidade e conectividade de municípios em uma mesma região, e sugerem a criação de redes de cooperação de gestão integrada, e a promoção de serviços capazes de atender à população em trânsito e suprir novos empregos, o que se propõe a partir de Bilbao Biscaia Next. É possível dizer, resumindo o que foi exposto, que os processos e modelos vigentes de requalificação urbana, ao transformarem cidades e regiões e agregar valor ao solo urbanizado, tem como contrapartida a produção de especialização produtiva diferenciada e desigual, e de setores planejados de atividade econômica, e ao mesmo tempo, de fragilidades e desequilíbrios como os sugeridos, e que políticas de reequilíbrio se fundamentam na coesão econômica e social e no planejamento inter e multiescalar, para implementar ações reequilibradoras. Requalificação e especialização produtiva parecem urgir, como contrapartida, a reestruturação contínua da composição social e populacional do território, a fim de mitigar as concentrações e desconcentrações produtivas e demográficas geradas, em um processo também contínuo de produção de desequilíbrios, raiz do Plano Bilbao Biscaia Next.

A policentralidade se converte então em método de indução de uma estrutura territorial de múltiplos centros nodais, que em tese tendem a uma equidade não-hierárquica, embora na prática sempre hierárquica, cujas relações de sinergia devem se distribuir em redes (NORDREGIO, apud CONTI, 2007). Estes autores apoiam a indução do processo policêntrico sob a gestão de autoridades supralocais (a União Europeia, os Estados e as regiões), e a cooperação de autoridades locais, estimulando a cooperação entre níveis, e estimulando o 
fluxo local, nacional e transnacional de atividades econômicas. Verifica-se uma tensão ideológica constante entre o enfrentamento da produção desigual do espaço (HARVEY, 2013) e uma visão política de produção de espaços reticulares, porque solidários, e passíveis de compensação de diferenças e desigualdades socioterritoriais.

Do ponto de vista espacial, o conceito de policentralidade remete à presença de múltiplos pontos, nós ou polos de desenvolvimento; uma concentração ao mesmo tempo descentralizada, e a difusão de atividades econômicas previamente concentradas em áreas e regiões menos desenvolvidas. Seu objetivo é encorajar o desenvolvimento em cidades que passam por estagnação econômica, e a diferença destes mecanismos com os da regeneração urbana posta em marcha nos últimos três decênios, pela qual passaram cidades em todo mundo, incluindo os ícones Baltimore, Barcelona, Sevilha, Bilbao e outras, é a inclusão de processos, planos e projetos de requalificação em esquemas e ordenamentos territoriais de âmbito regional ao nível das nações, e supranacional, incluindo os municípios como coparticipantes de planos e programas de desenvolvimento de múltiplas escalas, capazes de estabelecer redes de redes. O papel de tais redes é pois articular a especialização inteligente, planejada e integrada, a uma visão metropolitana e regional, passando a abordar as dimensões urbana e regional a um só tempo, e atendendo às disposições de ordenamento territorial endógenas e europeias.

\subsection{Programa Urbact III, União Europeia: a indução de redes de redes policêntricas e Bilbao Biscaia Next}

URBACT III é um Programa Europeu de Cooperação Territorial financiado por Fundos Europeus de Desenvolvimento Regional (FEDER), que articulam os Estados membros, com implementação agendada de 2014 a 2020. A troca de experiências entre cidades e outros níveis de governo visa promover políticas regionais de coesão socioterritorial, de acordo com a política da União Europeia de Estratégias de Especialização Inteligente - documento RIS3 (COMISSÃO EUROPEIA, 2017). Exige-se dos países membros um planejamento regional consistente, para que sejam contemplados com recursos do FEDER no horizonte de 2014 a 2020. O documento RIS3 da União Europeia foi elaborado ex-ante, como condição para que diferentes regiões da UE obtenham financiamento para Programas de inovação e 
desenvolvimento. A partir de então, a especialização inteligente passou a integrar a agenda comum de cidades que visam ter acesso a esses fundos de financiamento de planos e projetos. Os objetivos do Urbact III são implementar políticas urbanas sustentáveis, holísticas e participativas, aprimorar estratégias, planos e projetos urbanos, e assegurar que profissionais e políticos de todos os níveis compartilhem informações sobre os vários aspectos do desenvolvimento urbano sustentável. O conceito de cidade-região ou cidadeterritório fundamenta o Urbact, o que o conecta aos objetivos de Bilbao Biscaia Next depende da coordenação gestora, e articulação de níveis distintos de governo, visando ampliar capacidades, diversificar atividades, e implementar a mobilidade e a conectividade. Integram a rede InFocus - como parte do Urbact III - as cidades do Porto, Plasencia, Bilbao (lider dessa rede), Bordeaux, Grenoble, Turim, Frankfurt, Ostrava, Bielsco-Biala e Bucareste. InFocus-Smart Specialization at City Level é uma rede pioneira por implementar este conceito de política urbana e o desenvolvimento econômico, adotando a especialização inteligente para aprimorar atividades e gerar empregos nas cidades integrantes da associação, beneficiando múltiplas forças e agentes. Pressupõe seguir as estratégias RIS3 em nível regional, fomentando a governança em escalas diversas. O equilíbrio de prioridades regionais e locais é uma diretriz para que a cidade-membro se alinhe ao RIS3 (URBACT, 2017). Identificam-se oportunidades emergentes e recursos tais como talentos e empreendedorismo, inovação ou branding, e oferta da cidade como local propício aos negócios.

Uma estrutura institucional proativa, como agência local experiente em desenvolvimento econômico, para abordar temas como relações de trabalho, produção e produtividade ou investimentos internos e atração de talentos, é fundamental para o sucesso da implementação, e deve ser fruto da combinação de políticas RIS3 nas diversas escalas.

Replicar o método RIS3 automaticamente, de cima para baixo ao nível local, provavelmente leva a uma indesejável fragmentação, contrariando a definição de redes e compartilhamento. A implementação de programas dessa envergadura envolve um Grupo Local de Apoio, para estabelecer o diálogo das partes interessadas, e articular as determinações mais amplas do Urbact às políticas de desenvolvimento urbano-regionais. Em Bilbao, um Conselho da Cidade (Bilbao Ekintza), um Conselho Provincial (Câmara Legislativa de Biscaia, ou Deputación Foral), do Governo Basco - este responsável pela 
aplicação das estratégias europeias de RIS3 - alinham-se às Universidades, e ao Instituto Basco de Competitividade (Orkestra) (BILBAO EKINTZA, 2017). Pode-se dizer que esta é a estrutura intitucional que desenvolve Bilbao Biscaia Next.

O plano Bilbao Biscaia Next caminha em direção da cidade-região, e para alcançá-la, este método de planejar vem sendo considerado pelas instituições governamentais, Município de Bilbao e Comunidade Autônoma do País Basco (CAPB), como indispensável para dar continuidade à regeneração urbana que desde a década de 1990 investiu em serviços e serviços avançados, em um momento em que a atividade primaz industrial já em declínio não mais supria o emprego e atividade econômica necessários, para reformular o tecido produtivo e informacional que caracteriza a sociedade em redes (CASTELLS, 1999). Dessa maneira, uma das ações foi especializar Bilbao em serviços e serviços avançados.

Bilbao é o principal parceiro do InFocus, e vem trabalhando para enlaçar as cidades da rede a partir da especialização inteligente. Em 2014, Bilbao Ekintza organizou um workshop para estabelecer prioridades ao nível urbano, e articulá-las com o RIS3 do País Basco, denominado "Inovação e estratégia de especialização inteligente para Bilbao", que teve como principal resultado a identificação de 6 temas prioritários: Serviços de Negócios Intensivos de Conhecimento (SNIC), Turismo, Soluções Urbanas, Artes e Cultura, Ecotecnologia e Tecnologias aplicadas a Saúde. As políticas de desenvolvimento econômico da cidade foram revisadas, enfatizando redes de cooperação comercial e clusters, empreendedorismo, atração de investimentos e sociedade do conhecimento.

Atualmente, no quadro do URBACT-InFocus, Bilbao está avançando em duas direções, que se reforçam: i) promover uma interação mais efetiva com o RIS3 basco; ii) enfocar três domínios: terciário avançado, economia criativa e economia digital, explorando suas relações, enfatizando a industrialização avançada, a mais importante prioridade do RIS3 basco. Para tanto, realiza estudos desde 2013 apoiados por Orkestra sobre economia criativa, especialização produtiva e detecta setores econômicos e territórios que podem compartilhar ações para um desenvolvimento conjunto.

A implementação das estratégias exigiu que Bilbao Ekintza criasse uma plataforma colaborativa, que reúne os parceiros: a governança multinível, a equipe de gerenciamento RIS3 do País Basco e a Câmara dos Deputados de Biscaia como o órgão com capacidade de 
financiamento, centros de pesquisa e grupos de reflexão (Tecnalia-Technology Corporation e Orkestra - Instituto Basco da Competitividade), o setor privado e organizações como Câmara de Comércio, TI GAIA, EIKEN audiovisual e AVIC engenharia e consultoria, bem como universidades públicas e privadas (UPV / EHU, Universidade de Deusto e Universidade de Mondragón).

Esta plataforma colaborativa e essa estrutura institucional são os mais importantes instrumentos do URBACT Local Group (ULG), que Bilbao estabeleceu no âmbito do Programa InFocus. O grupo local é uma ferramenta para envolver as autoridades regionais e a integração ao RIS3 basco, num diálogo com a cidade, demonstrando a vocação interescalar do Programa. Outras cidades parceiras no InFocus, como Porto, Bucareste e Frankfurt estão replicando esse método, e mais resultados serão compartilhados, pois Planos de Ação Integrados para a rede serão elaborados em 2018. O Plano Bilbao Biscaia Next, beneficiário do InFocus e de tal base institucional, é uma estratégia e um meio para alcançar a cidade-região, para o que a visão setorial de Planos e Projetos Urbanos dá lugar a uma complementaridade destes, exigindo um novo aporte conceitual, como o de "Projetos Urbanos Estratégicos" (VEGARA; RIVAS, 2004). Estes incluem no território em transformação e até mesmo nos próprios artefatos arquitetônicos funções, atividades e conexões - como mediações legítimas de articulação econômica e social, de acordo com as diretrizes locais e regionais dos planos. Projetos Urbanos Estratégicos procuram superar a hierarquia de planos e projetos, e o consolidado "planejamento em cascata", ultrapassando a submissão de níveis em direção a uma integração destes (DETTORI, 2014). Tal integração deve levar em conta características socioambientais e culturais dos territórios (SABATÉ, 2004), sugerindo uma gestão inteligente da paisagem cultural e dos recursos naturais como culturais, econômicos e sociais.

Aspectos críticos relativos à proposta do plano e à sua implementação devem levar em conta as vocações dos territórios afetados, suas características endógenas, e o potencial de desenvolvimento de que dispõem, uma vez na situação colaborativa proposta pelas redes que integram. 


\section{Bilbao Biscaia Next - planejamento territorial e projetos urbanos estratégicos}

Bilbao Biscaia Next é um plano multiescalar para transformação socioeconômica por meio da especialização inteligente, implementação de vantagens competitivas mediante pontos fortes, oportunidades e desequilíbrios territoriais, com o fim último de prover ações capazes de diminuir diferenças e desequilíbrios de produtividade, renda e acesso a serviços nos diversos municípios que afetam ao Plano (ESTENSORO; LARREA, 2015). A partir da investigação sistemática de oportunidades de I + D - Inovação e Desenvolvimento, pressupõe contribuir para a criação de redes que conectam especialidades produtivas complementares, em âmbito regional (id., ibid), intermunicipal, interprovincial e inter autonômico. A implementação de tais amplas redes depende de prioridades que influem nas políticas territoriais e na distribuição de atividades: ciência e tecnologia, indústrias, atividades urbanas ligadas à cultura, informação, negócios, saúde, educação, habitação, espaço público, etc.. A implementação de um plano como o que se apresenta requer uma política territorial de acordo com seus objetivos, e este é um desafio que pode levar ao êxito ou fracasso de suas amplas pretensões.

Iniciativa da Prefeitura de Bilbao e do Governo Autonômico de Biscaia (Comunidade Autônoma), é fundamentado por uma pesquisa-ação ${ }^{1}$ que vem desde 2013 sendo realizada por Orkestra, Instituto Basco de Competitividade, e as Universidades de Deusto, Mondragón e UPV - Universidade do País Basco.

Conta ainda com a parceria do Governo da Espanha, Governo Regional de Biscaia e da agência Bilbao Ría 2000, implementadora histórica das ações de recuperação urbana e do plano metropolitano, em marcha desde fins dos anos 1990 (ABASCAL, 2004). No País Basco, o âmbito regional tem expressão na atuação da Comunidade Autônoma como ente administrativo para a realização dos objetivos de um planejamento integrado e em rede. 0 entendimento do planejamento sustentável envolve dimensões tais como a regulação da paisagem, redução de deslocamentos, o desenvolvimento da policentralidade, a

\footnotetext{
1 “A pesquisa-ação é um tipo de pesquisa social que é concebida e realizada em estreita associação com uma ação ou com a resolução de um problema coletivo e no qual os pesquisadores e os participantes representativos da situação da realidade a ser investigada estão envolvidos de modo cooperativo e participativo.( Thiollent,1985:14, apud BALDISSERA, 2001).
} 
acessibilidade ao conjunto de equipamentos e serviços disponibilizados regionalmente, redução do consumo de água e energia, promoção de uma coesão socioterritorial com participação social em todo o processo (EUSKADI.EUS, 2018). A Comunidade Autônoma do País Basco desempenha papel fundamental como rota de conexão norte-sul e leste-oeste no território espanhol, e ocupa uma superfície muito menor que as comunidades vizinhas, com densidade populacional onze vezes maior que Castela e Leão, por exemplo (LOZANO, 2003).

As Diretrizes de Ordenamento Territorial (DOT, 2017) definem os critérios de ordenação do meio físico, pautados na conectividade, mobilidade, uso de múltiplos modais de transportes, e entre estes, os ferroviários de alta velocidade (TGV), prevendo formas de governança para sua atualização. A articulação policêntrica é fundamental à própria implementação dessas diretrizes, formando conexões reticulares entre seus diversos pontos, e considerando o desenvolvimento urbano função das correspondências entre sistemas de transportes coletivo e usos do solo, para alcançar uma coordenação com Projetos Urbanos (EUSKADI.EUS, 2018). O documento das DOT, desde sua versão de 2012, reflete a importância de estruturas reticulares, pautadas no aumento da velocidade dos meios de mobilidade (com a proposta do trem de alta velocidade), bem como prevendo um tecido digital de conexões ou redes digitais (ABASCAL; BILBAO, 2011). Tal planejamento integrado proposto hoje pela CAPB visa, entre outros objetivos, à sustentabilidade, em termos de economia de consumo energético, consumo de água e de meios e recursos de produção. Os meios de integração entre as DOT e demais instrumentos de planejamento se fundamentam na mediação de planos específicos que se referenciam mutuamente, tais como os PTP - Plano Territorial Parcial e os PGOU - Plano Geral de Ordenamento Urbano, no âmbito dos municípios.

O PTP, para a Área Metropolitana de Bilbao (GOVERNO BASCO, 2006) regula a ordenação territorial e os critérios urbanísticos com base nas DOT, a partir de Convênio de Cooperação entre o Departamento de Urbanismo y Vivienda do Governo Basco, e Departamento de Urbanismo da instituição que representa o governo autonômico, a Câmara Provincial de Biscaia. Ao incorporar as normas de ordenamento territorial, prevê a compatibilização com o planejamento dos 35 municípios que a Região Metropolitana de Bilbao abrange. Foi aprovado em 2006, e define a estratégia territorial em um âmbito denominado Área Funcional (FORUM ALDUNDIA, 2017). O PGOU é um instrumento estratégico para definir as 
características futuras da cidade, sendo ainda um documento jurídico, previsto pela regulamentação urbanística da Comunidade Autônoma Basca. É indispensável a ordenação integral do território e para a definição dos usos do solo, a partir dos quais são escolhidos os principais equipamentos, as infraestruturas e áreas verdes, os espaços livres do município e os artefatos arquitetônicos relevantes. Estes planos em escala regional e local replicam em suas diretrizes os mesmos princípios presentes nas DOT, com ênfase no município na contenção da urbanização difusa e desregulada, o aproveitamento de espaços ociosos e resgate de áreas degradadas ou obsoletas. É possível dizer que duas políticas se complementam, a policentralidade reticular e o aproveitamento máximo do solo ao nível municipal, a fim de reverter áreas ociosas, obsoletas e degradadas. Tanto os PTP como PGOU se fundamentam em critérios de minimização do consumo de solo e sustentabilidade de novos crescimentos urbanos, favorecendo a densidade nos lugares urbanizados, evitando a urbanização difusa. Em nível municipal a sustentabilidade é hoje um dos principais objetivos, com a implementação de sistemas integrados de informação territorial e maior controle da construção. O PTP é o instrumento que coordena as DOT, como um guia supramunicipal que orienta a redação do PGOU de cada município (FORUM ALDUNDIA, 2017).

O País Basco conta hoje, portanto, com instrumentos de planejamento que podem vir a contribuir para articular distintas escalas e estabelecer os meios para a consecução de Bilbao Biscaia Next, em que um dos desafios é integrar o plano econômico ao desenvolvimento urbano e regional, propriamente.

Uma das realizações urbanísticas da cidade de Bilbao, diretamente envolvida com a política de especialização inteligente em marcha e com Bilbao Biscaia Next é o Projeto de Zorrotzaurre, um Grande Projeto Urbano que abrange 80 hectares, com master plan de autoria da arquiteta angloiraquiana Zaha Hadid, que combinará habitação e usos múltiplos, com áreas empresariais destinadas a sedes de empresas e serviços à produção. Zorrotzaurre conta neste momento com projeto aprovado para a Unidade de Execução 1, em uma extensão urbanística que ocupa uma superfície total de 838.781 metros quadrados, e permitirá transformar esta antiga zona industrial.

O projeto reforça que espaços urbanos proporcionam oportunidades de especialização inteligente, neste caso, serviços e serviços avançados, e são objeto de estudos e de 
articulação, materializando intervenções urbanísticas no âmbito de Bilbao Biscaia Next. Zorrotzaurre é um parque tecnológico integrado a outros usos, e aprofunda a especialização produtiva em serviços à produção, serviços digitais e corporativos, na expectativa de criar empregos e amplificar a vocação terciária e para o terciário avançado projetada pela cidade, combatendo a migração populacional e atraindo mão de obra qualificada. O projeto de Zorrotzaurre, cuja obra de abertura do canal de Deusto possibilitou minimizar o risco de inundações na área e no entorno circundante de Bilbao, é uma forma de aprofundamento e potencialização da especialização produtiva que Bilbao já detém (ORKESTRA, 2014), a partir de estudos que as diversas instituições envolvidas com Bilbao Biscaia Next vêm desenvolvendo, enfocando a criação de um novo tecido econômico e social baseado na criatividade, inovação e tecnologia. Desde 2008, juntamente com o avanço do projeto de regeneração urbana, vêm se instalando na futura ilha atividades culturais, artísticas e de lazer, marcando uma vocação para inovação artística. Este processo se iniciou em 1998, quando a Asociación Cultural Hacería se instalou em Zorrotzaurre, recuperando um antigo espaço de indústria para teatro, música e dança (PREFEITURA DE BILBAO, 2018). Em 2008, já com o projeto urbanístico em marcha, surgiu o projeto ZAWP (Zorrotzaurre Art Work in Progress) para implementar atividades artísticas, juntamente ao processo de especialização produtiva já em curso.

A Comissão Europeia apoiou o projeto, e dotou-o em 2015, entre 378 iniciativas de outros países, para incentivar a competitividade no campo da inovação, de 4.600,000 euros (80\% dos pressupostos necessários à implementação), para a conversão da ilha de Zorrotzaurre em um centro de referência para a especialização inteligente em serviços avançados (UIA URBAN INNOVATE ACTIONS, 2016). Contará com um parque tecnológico urbano, o primeiro da Espanha, ficando a cargo da Câmara Provincial de Biscaia e Prefeitura bilbaina. O projeto visa atingir, segundo o atual Prefeito de Bilbao Juan Mari Aburto (EITB.eus, 2016) três objetivos fundamentais, desenvolvimento econômico, social e atração de investidores estrangeiros. Com uma mescla de usos, entre residencial e atividades econômicas vinculadas à economia digital, Zorrotzaurre tem como principal foco o Parque Tecnológico Urbano.

Cabe ressaltar que a criação desse parque tecnológico, elevando a especialização inteligente em serviços avançados em Bilbao, o que atrairá empresas e empregos, é também uma 
forma de concentração de renda e valor da terra, e de indução de mobilidade populacional a outros municípios conectados e relativamente próximos, reforçando ao mesmo tempo esvaziamentos e declínios econômico-produtivos e fortalecendo outros polos, o que justifica uma possível ação do Plano Bilbao Biscaia Next. O que aparentemente parece consistir em vantagem competitiva para a cidade e a região, pode representar um aprofundamento dos desequilíbrios regionais, pois outros polos e municípios com alta concentração de renda e outros parques tecnológicos já se encontram localizados, como adiante veremos.

\section{O território de Bilbao Biscaia Next: especialização produtiva e desequilíbrios regionais}

A política espacial multiescalar e policêntrica prevista por Bilbao Biscaia Next procura incluir os municípios sob sua gestão em um modelo de desenvolvimento territorial que prevê equidade, ao considerar a competitividade e a solidariedade intermunicipal. À diferença da recuperação urbana praticada até os anos 2000, tal opção policêntrica visa integrar municípios que hoje apresentam indicadores socioeconômicos distintos, acarretados pela transformação funcional e de atividades tradicionalmente primazes, tais como a indústria, buscando uma sinergia a partir das potencialidades e atividades econômicas existentes, e estabelecendo redes de cooperação, a fim de tirar proveito de possíveis parcerias e minimizar desequilíbrios.

O Plano considera como âmbito geográfico o território que inclui empresas de diversos setores e prestadores de serviços, localizados na Comunidade Autônoma do País Basco, e empresas associadas, incluindo os municípios da Grande Bilbao, estendendo-se até os limites de Castro, na Cantábria, Eibar, em Guipúzcoa, e o limite de municípios da província de Alava, tais como Llodio, Amúrrio, Aiala, Arseniaga, Oquendo, que ao estão também no escopo de Bilbao 45, como é possível verificar no mapa da Figura 1.

Ao abranger municípios fora de Biscaia, sinaliza-se a necessidade de integração interadministrativa, pois as normas de ordenação territorial do País Basco não se estenderão à Cantábria e outras províncias afetadas, exigindo ações conjuntas e convênios 
interautonômicos para que possa haver uma eventual solução ao impasse, e um efetivo planejamento que inclua um território administrativa, social e economicamente heterogêneo.

A transformação das capitais, embora indispensável, não exclui e não é autônoma em relação a outros territórios sob sua influência e gestão. Verificam-se, na região prevista para aplicação do Plano, lugares em declínio, e outros, como por exemplo, Zamudio, na Grande Bilbao, que por contar com um parque tecnológico implementado desde 1988, apresenta hoje elevada renda per capita, por ter se especializado em inteligência ambiental, infraestrutura de conectividade e eletrônica, ofertando serviços e produtos, assessoria tecnológica, assistência técnica, análise e ensaios de certificação de produtos e formação e difusão tecnológica bem como incubadoras de novos negócios, baseados em novas tecnologias (FORUM ALDUNDIA, 2017b). A fim de conhecer os pontos fortes e fracos do tecido produtivo, para justificar o Plano, o Instituto Basco de Competividade - Orkestra (2014) vem realizando pesquisas de especialização produtiva, passando a registrá-las setorialmente: manufaturas, serviços, serviços intensivos em conhecimento (serviços avançados a empresas), de modo comparado com índices da CAPB, Espanha e UE, dados originalmente disponibilizados por EUSTAT (2018). A análise da especialização produtiva é um importante instrumento para investigar a potencialidade de inovação do território, oportunidades e debilidades dos diferentes setores.

A distribuição e a concentração da especialização produtiva pode ser verificada no mapa seguinte, conforme seus principais eixos de localização, e possibilita compreender comparativamente a variação de renda per capita e as características socioeconômicas do território alvo do Plano.

Os efeitos de desconcentração populacional, desequilíbrios regionais e variação de renda per capita verificados entre os municípios pode ser visualizado nos mapas das Figuras xxxx, xxxx, e exemplificado por Castro Urdiales, cidade litorânea fronteiriça com Biscaia que dista 35 km de Bilbao, e está incluído no escopo do Plano. 


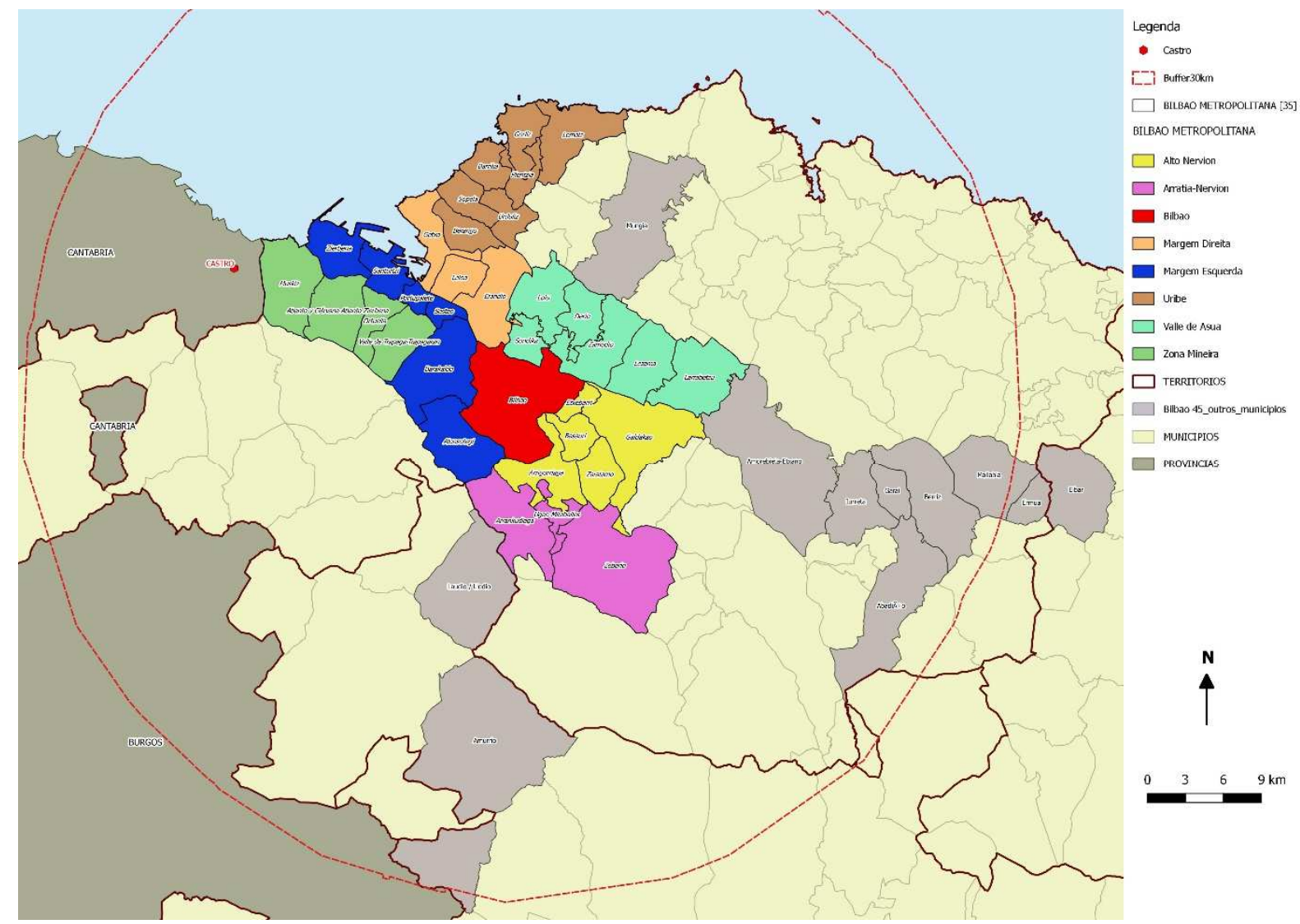

Figura 1 Mapa de abrangência do Plano Bilbao 45 - o círculo envolve o território alvo do Plano Fonte: elaboração Profa. Ms. Carolina Bracco Aguilar - FAU Mackenzie, a partir de mapa base do IDEE, disponível em: http://www.idee.es/

Castro vem demonstrando um afluxo de moradores em que mais de $40 \%$ da população real é originária da província de Biscaia. Esse contingente mantém seu registro cível e fiscal (empadronamiento, em espanhol) em Castro. Os preços de residências em Castro são da ordem de $50 \%$ mais baratos que em Bilbao (BILBAO EKINTZA, 2017). O preço médio do metro quadrado no primeiro semestre de 2017 em Bilbao era de 2.943 euros (BILBAO EKINTZA, 2017), enquanto que em Castro se situa em média em torno de 2.037 euros por metro quadrado (SER CANTABRIA, 2017). A renda per capita de Castro é de 28.926 euros (AGÊNCIA TRIBUTÁRIA G.E., 2018), sendo a segunda renda maior entre os municípios da Autonomia da Cantábria, cuja média é de 20.950 euros. 


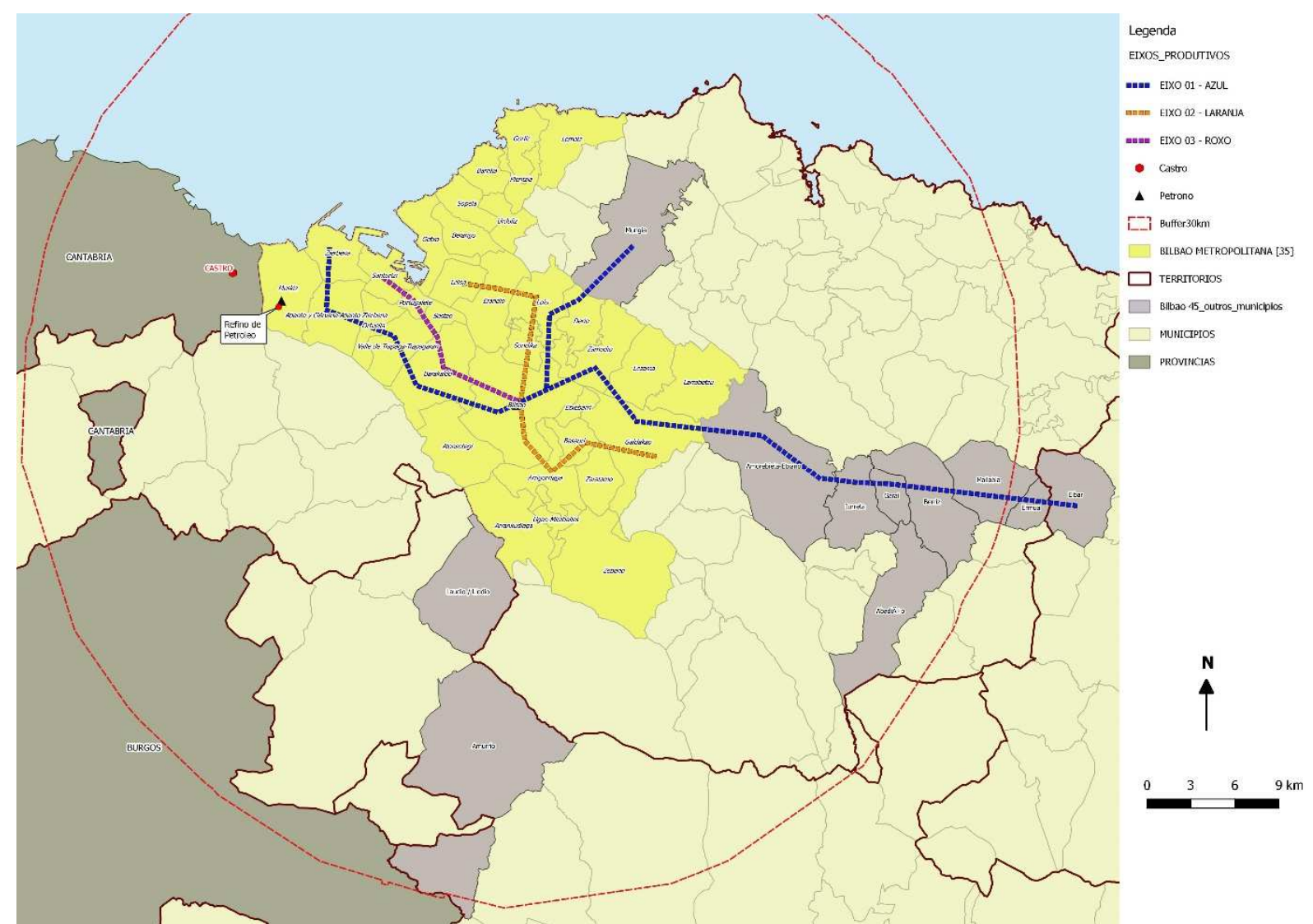

Figura 2 Principais eixos de especialização produtiva na região objeto do Plano, tendo o município de Bilbao como epicentro

Fonte: elaboração Profa. Ms. Carolina Bracco Aguilar - FAU Mackenzie, a partir de dados disponíveis em CESCE, https://www.informa.es/

A renda per capita de Castro aproxima-se à de Bilbao, que é de 29.807 euros, sendo a de Biscaia 29.432 euros. A Prefeitura de Castro estima entre 20.000 e 30.000 o número de "cidadãos invisíveis" de Castro Urdiales, oriundos da província de Biscaia e que não estão registrados nela, e sim em nesta última província, o que levou a municipalidade a realizar uma intensa campanha para que esse contingente silencioso se faça visível e formalize seu registro nesse município. Em Castro Urdiales consta o censo de 2017 de 31.817 registrados (Instituto Nacional de Estatística 2018), que somados aos 20.000 ou 30.000 invisíveis, totaliza uma população de aproximadamente 52.000 a 62.000 pessoas. A campanha, que tem como mote queremos verte, luta para reduzir a população que não tem registro, sequer paga impostos em Castro, a não ser o imposto predial, considerado alto, de vez que as variações do preço da terra, devido ao aumento da escassez pela procura de solo e bens imóveis, vem fazendo oscilar o custo desse tipo de imposto. O déficit para os cofres públicos castrenhos, devido ao lapso de recolhimento de impostos sobres a população "invisível" é da ordem de 4 a 6 milhões de euros, que poderiam ser investidos em melhorias, serviços e 
equipamentos públicos (MUCHOCASTRO, 2018). Por cada pessoa não registrada o Estado deixa de receber 200 euros, vários milhões de euros ao ano.

Os biscainhos moradores em Castro aludem a que lhes é possivel, mantendo registro em Biscaia, aceder ao atendimento médico de urgência ou a determinadas especialidades no hospital biscaino de Cruzes (município de Baracaldo, na Grande Bilbao), muito mais próximo do municipio de residência dos que os que Ihes correspondem na Cantábria, em Laredo ou Santander. No que tange ao transporte entre as duas comunidades autônomas, muitos residentes em Castro trabalham em Biscaia, e o governo cantábrico não subvenciona transportes públicos que conectem Castro a província biscaina.

De modo que isso vem levando a exigências da população residente em Castro Urdiales, de que o governo autonômico proveja um bilhete de transporte, ao estilo do Creditrans biscaino, um bilhete integrado que facilite viagens entre ambas as regiões. A falta de integração e co-gestão entre duas regiões fisicamente tão próximas vem causando desequilíbrios fiscais e econômicos, que afetam tanto ao País Basco como à Cantábria; tanto uns como outros perdem - em população, em impostos, em serviços compartilhados. Desequilíbrios como este justificam que Castro esteja no âmbito de Bilbao 45, à espera de uma solução. A situação levou a que o partido castrenho Anexión a Vizcaya busca recuperar esse vínculo com os vizinhos, sugerindo convênios que possam garantir os serviços (PREFEITURA DE CASTRO, 2018). O fenômeno se deve à emigração de parte de biscainos em busca de solo de valor mais acessível, deixando Bilbao, mesmo que lá continuem a exercer suas lides profissionais.

Castro vem sendo considerado no escopo dos estudos de Bilbao Biscaia Next, pois situações como a descrita afetam a ambas as regiões autonômicas, Cantábria e Biscaia, e atestam efeitos da requalificação urbana de Bilbao no valor da terra, promovendo movimentos emigratórios entre municípios. No caso desse município, trata-se de um local eminentemente de moradia, antes quase que exclusivamente de veraneio, e não prioritariamente de trabalho, e que passou a compensar pela proximidade a Bilbao, contribuindo para produzir flagrantes diferenças de especialização produtiva no território de Bilbao Next. 


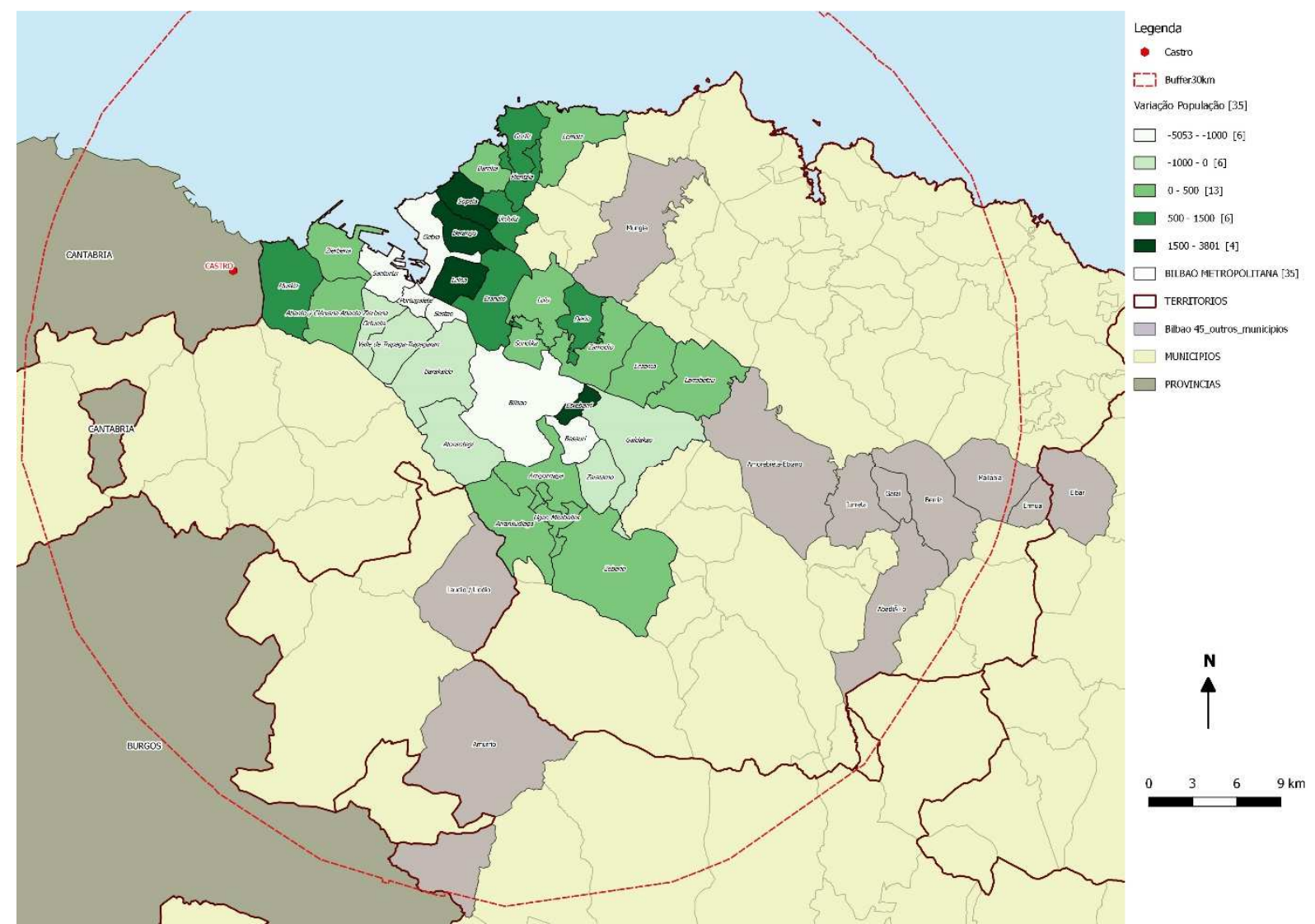

Figura 3 Mapa da variação populacional nos municípios abrangidos pelo Plano

Fonte: elaboração Profa. Ms. Carolina Bracco Aguilar - FAU Mackenzie, espacialização dos dados sistematizados nos Quadros 1 e 2

O projeto urbano de Zorrotzaurre, a última grande intervenção urbana prevista para Bilbao e que recebeu recursos para a sua realização, poderá criar ou não um novo tecido especializado para o setor terciário e terciário avançado, que poderá beneficiar a toda região-alvo do Plano; no entanto, consumirá um expressivo montante de recursos, podendo ainda concentrar atividades produtivas especializadas e renda, e descompensar outras localidades, ou gerar novos deslocamentos e valorização da terra, como revela o caso de Castro.

As desigualdades regionais apontadas pelas diferenças de renda per capita e variações de população nos municípios da Grande Bilbao e Bilbao 45, estão sistematizados no Quadro 1, que demonstra conflitos e desequilíbrios, expressos nas diferenças da valorização da terra e movimentos de população entre os diversos municípios, decorrentes de sua estagnação, prosperidade ou declínio econômico.

Esse é o desafio de Bilbao Biscaia Next, entre a requalificação urbana e a especialização produtiva, e a concentração desconcentrada, tentando prover o equilíbrio da cidade região. 


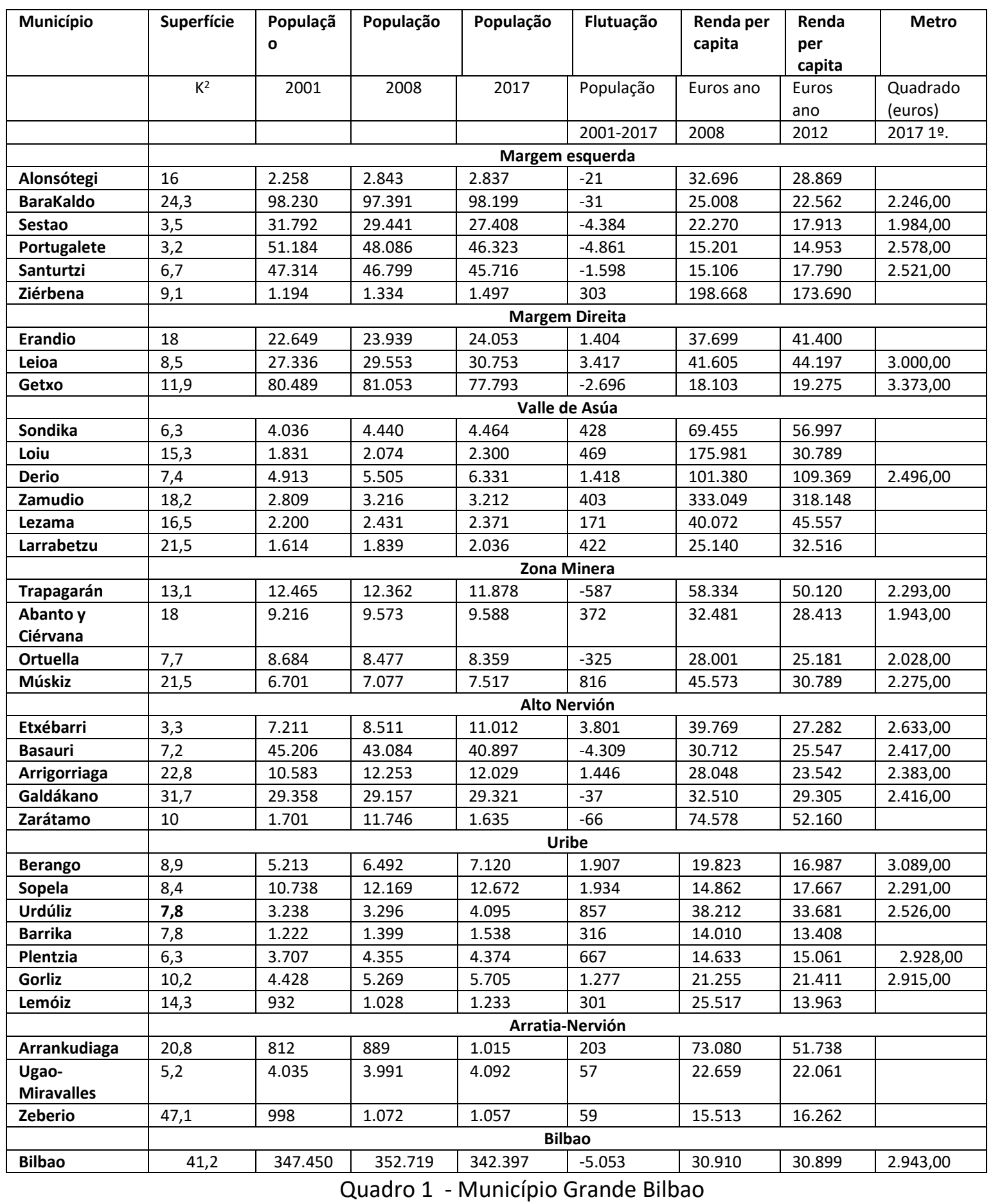

Fonte: elaboração dos autores, a partir de dados de Eustat, 2018 Disponível em:

Pesquisa de valor de solo (m2) - Disponível em: EUSTAT, 2018 (para os municípios da Grande Bilbao). Os dados de Castro Urdiales foram obtidos em INE Instituto Nacional de Estadística de España, 2017. 


\begin{tabular}{|l|l|l|l|l|}
\hline \multicolumn{1}{|c|}{ Município } & \multicolumn{1}{|c|}{ Província } & \multicolumn{1}{c|}{$\begin{array}{c}\text { Renda per capita } \\
\mathbf{2 0 0 8}\end{array}$} & $\begin{array}{c}\text { Renda per capita } \\
\mathbf{2 0 1 7}\end{array}$ & $\begin{array}{c}\text { Metro } \\
\text { Quadrado } \\
\text { 2017 10. }\end{array}$ \\
\hline Llodio & Alava & 18.544 & 30.391 & $1.931,0$ \\
\hline Amurrio & Alava & 10.321 & 44.597 & \\
\hline Ayala & Alava & 2.883 & 25.176 & \\
\hline Arseniaga & Alava & 1.898 & 21.151 & \\
\hline Okondo & Alava & 1.176 & 25.888 & \\
\hline Eibar & Guipúscoa & 27.134 & 23.641 & $2.035,0$ \\
\hline
\end{tabular}

Quadro 2 - Área de influência de Bilbao 45

Fonte: elaboração dos autores, a partir de dados de Eustat, 2018 Disponível em: EUSTAT., 2017. Disponível em: http://www.eustat.eus/municipal/datos_estadisticos/bilbao.html. Acesso em 21 de dezembro, 2017.

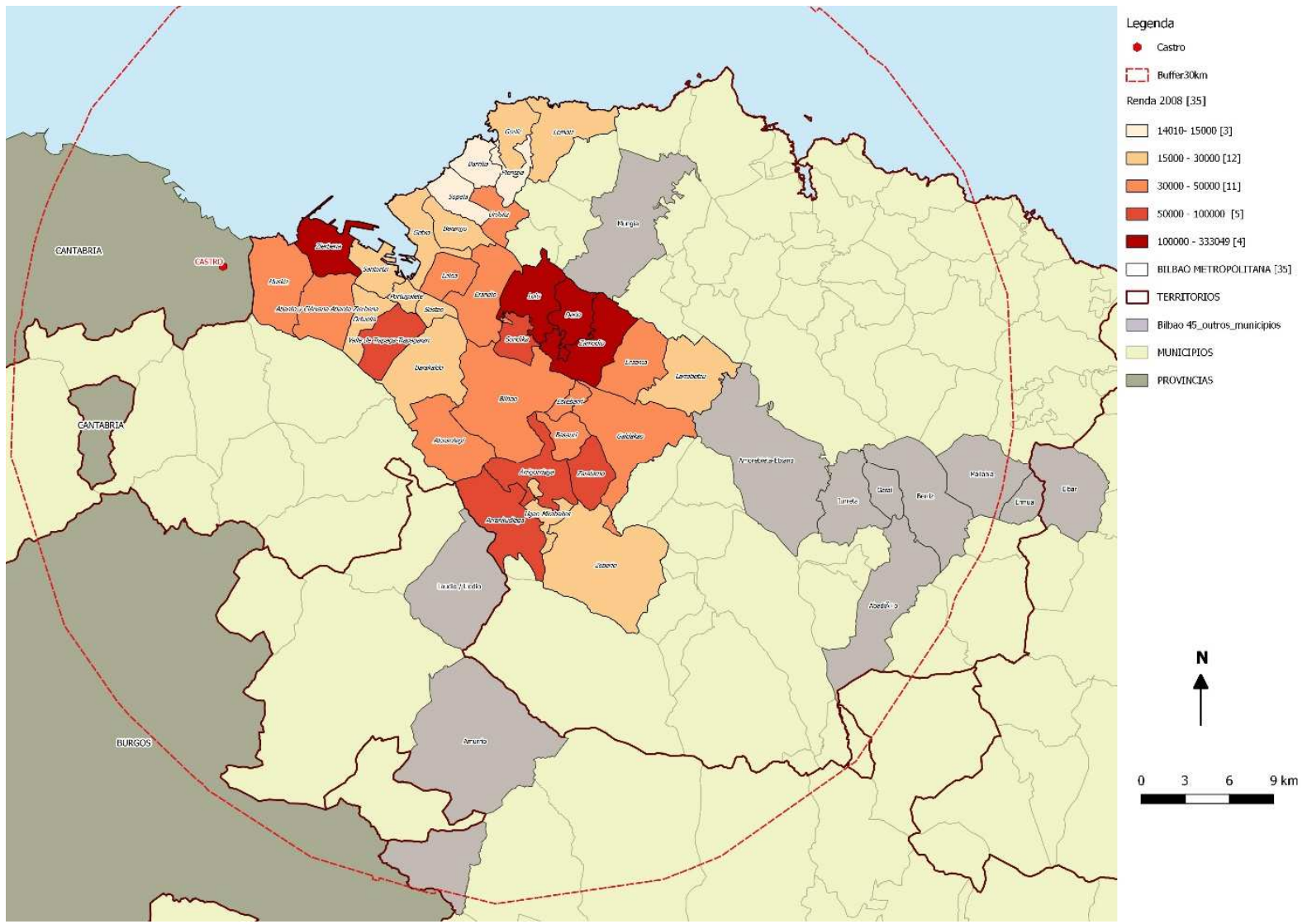

Figura 4 Mapa da variação de renda per capita dos municípios alvo do Plano Bilbao 45 - 2008 Fonte: elaboração Profa. Ms. Carolina Bracco Aguilar - FAU Mackenzie, , espacialização dos dados sistematizados nos Quadros 1 e 2. 


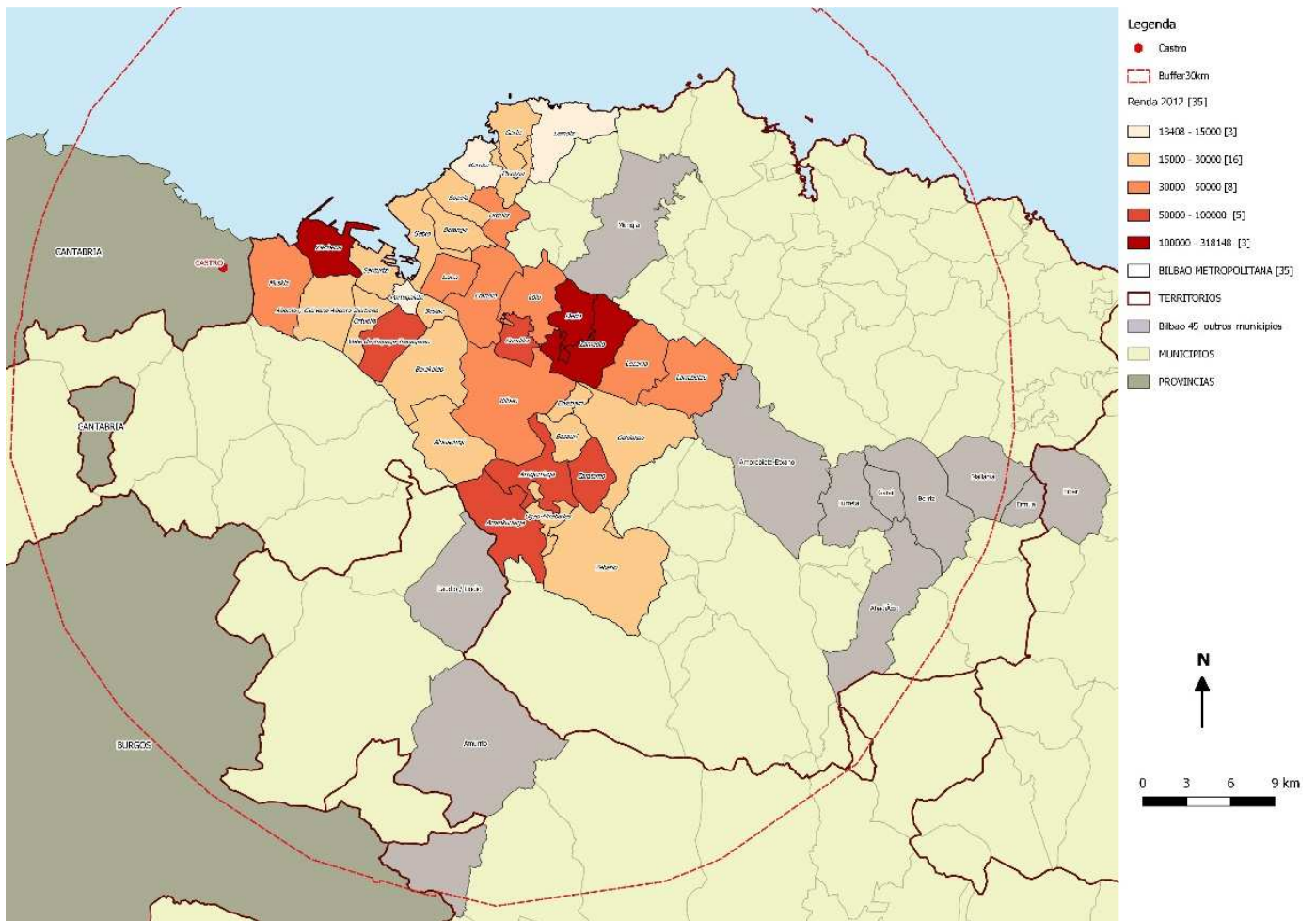

Figura 5 Mapa da variação de renda per capita dos municípios alvo do Plano Bilbao 45 - 2012 Fonte: elaboração Profa. Ms. Carolina Bracco Aguilar - FAU Mackenzie, espacialização dos dados sistematizados nos Quadros 1 e 2

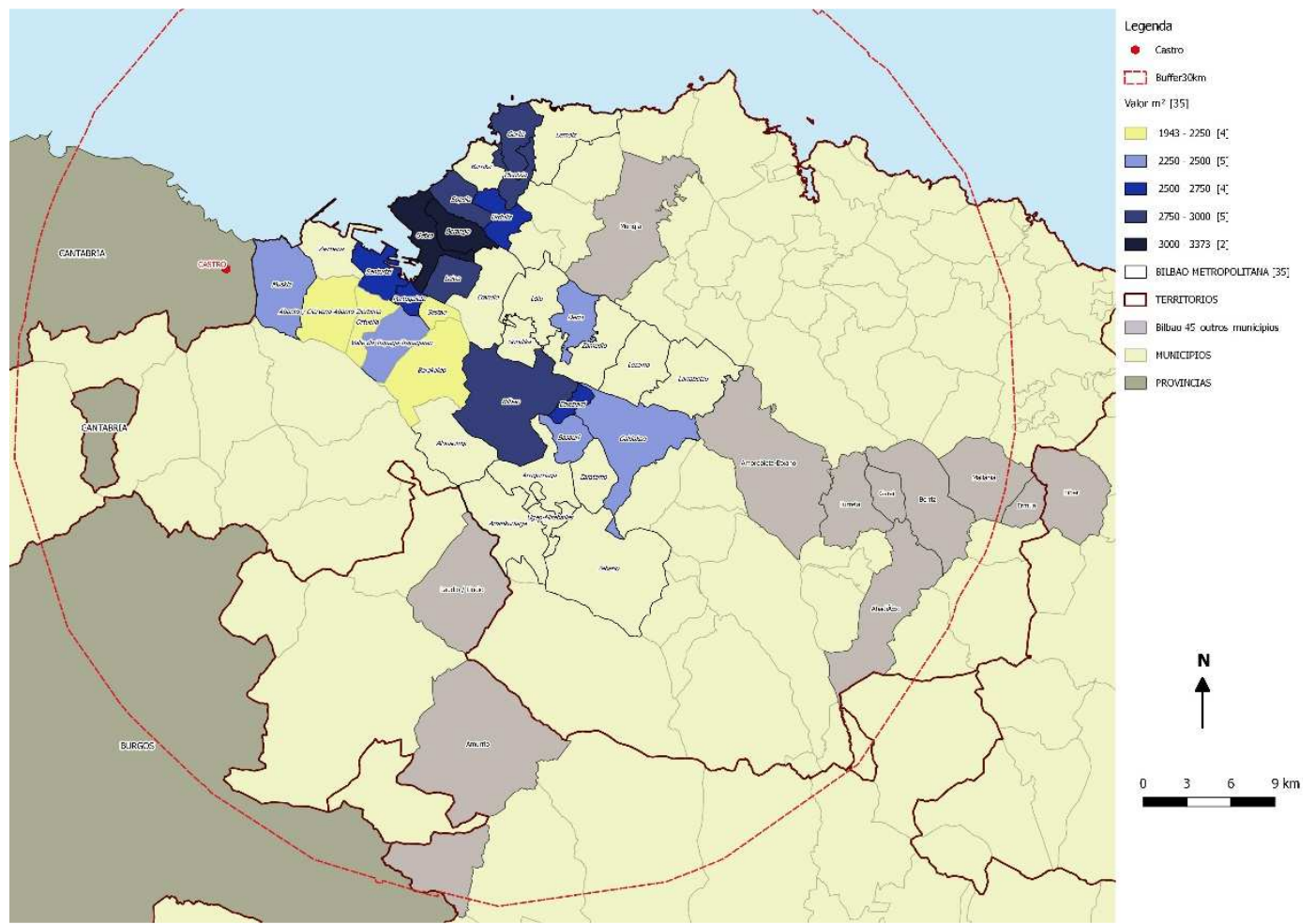

Figura 6 Mapa da variação do valor da terra dos municípios alvo do Plano Bilbao 45 Fonte: elaboração Profa. Ms. Carolina Bracco Aguilar - FAU Mackenzie, , espacialização dos dados sistematizados nos Quadros 1 e 2 


\section{Resultados e análises a partir da especialização produtiva dos municípios que integram Bilbao 45}

Os dados, apresentados nos quadros e mapas anteriores fornecem informações sistematizadas para estabelecer parâmetros comparativos do comportamento dos municípios da Grande Bilbao, e destes em relação aos demais municípios de Bilbao 45, no que se relaciona à variação de população, renda per capita e valor do solo, quando foi possível agregar este último valor.

Ao analisá-los, deve-se mencionar que a renda per capita de 2008 segue sendo referencial, pois esse ano marca o início da crise econômica e imobiliária na Espanha, tendo havido até 2012 uma retração de 6\%, devido a deflação. Verifica-se ainda que o índice geral de renda na província de Biscaia de 2015 é praticamente o mesmo de 2008, sendo esta última data referência (EUSTAT, 2017).

É possível ainda perceber movimentos populacionais entre os municípios de Biscaia, e entre estes e outros municípios no escopo do Plano, presentes em outras Autonomias, provocados pela elevação, retração ou declínio, ou ainda, transformação de suas especializações produtivas históricas, de maneira que relativamente ao valor da terra, é possível inferir as razões das flutuações populacionais, e por comparação, compreender os desequilíbrios produtivos, de renda e população entre os municípios, demonstrando assim uma gentrificação em processo. A análise permite então justificar o Plano Bilbao Biscaia Next, embasado em diferenças expressivas de performance entre municípios próximos, bem conectados e flagrantemente afetados de maneira muito distinta em relação ao seu desenvolvimento socioeconômico. No que cabe especialmente ao município de Bilbao, este não apresenta especialização produtiva expressiva em manufaturas, que comparece com força em outros municípios da região abrangida por Bilbao 45, o que se evidencia também nos mapas apresentados. A especialização produtiva de Bilbao, que se mantém com índices superiores aos da União Europeia (UE-28) é em serviços e serviços avançados, (KIBS Knowledge Intensive Business Services), a saber, armazenamento e atividades anexas aos trasnportes, edição, atividades de programação e emissão de rádio e televisão, serviços jurídicos, contabilidade, auditorias e assessoria fiscal, telecomunicações, publicidade e 
estudos de mercado, atividades relacionadas a agências de viagens e afins, investigação científica em ciências sociais e humanas (ORKESTRA, 2014).

O município de Bilbao, propriamente, apresenta especialização produtiva em serviços, mas renda per capita inferior a outros, por exemplo como Zamudio, Echévarri, Sondica ou Ciérvana, o que indica a inclinação para desenvolver-se como centro de serviços avançados, com o projeto de Zorrotzaurre e o Parque Tecnológico urbano. O último grande Projeto Urbano para a ilha de serviços avançados ligados à tecnologia de informação deverá tornar Bilbao atraente para empregos, no entanto, continuará elevando o preço do metro quadrado, como fruto da requalificação. O movimento pendular de população residente em municípios a 45 minutos será então reforçado pelo sucesso de Bilbao. No entanto, os resultados não autorizam concluir pelo sucesso e eficiência do Plano, sobretudo ao pensar que o Grande Projeto Urbano de Zorrotzaurre, beneficiário dos recursos do FEDER, poderá contribuir para aprofundar os desequilíbrios regionais, contrariando o discurso de sinergia do Plano, pois se localiza próximo a outro parque tecnológico de monta - em Zamudio, evidenciado pelo mapa de especialização produtiva.

Tais variações podem ser observadas em relação a Sestao e Baracaldo, que juntos a Alonsótegi, Portugalete, Santurtzi e Ciérvana, se localizam na região da Margem Esquerda do Nervión, as indústrias siderúrgicas e os Altos Fornos de Biscaia neles se localizavam. Ao se desindustrializarem, desde os anos oitenta do século $\mathrm{XX}$, as indústrias remanescentes mais especializadas do setor siderúrgico se mudaram para o município de Echévarri (PREFEITURA DE ECHÉVARRI, 2018). Este município detém ainda hoje polígonos industriais, o que justifica o relativo aumento de população e da renda per capita neste, com o valor de solo, entretanto, bem abaixo das regiões de custo mais elevado, relativamente a outras localidades. Echévarri concentra riqueza e mantém o valor da terra baixo, atraindo população.

Gorliz, Barrica, Berango, Sopelana, Guecho, Urdúliz, Plencia e Lemóiz são municípios de orla marítima (Ver MAPA 4) que se encontram na porção final do Rio do Nervión, próximos à desembocadura ("Ría). São servidos pelo metrô, que se estende por esse eixo metropolitano, bem conectados e parte do escopo de Bilbao 45. Detêm hoje renda per capita bem abaixo da média do País Basco (29.000 euros), assinalando baixa produtividade, e valor do metro quadrado ainda relativamente alto, à exceção de Urdúliz, único que não 
tem saída para o mar, e é sede da empresa Lointek ${ }^{2}$, fabricante de equipamentos industriais de grande porte, que emprega mão de obra qualificada, e mantém uma renda média per capita alta. Os municípios costeiros e balneários, como os citados, comportam grandes imóveis de valor elevado e baixa densidade, e geram movimentos de emigração a outros municípios mais bem adaptados ao processo produtivo. Portugalete, município da margem esquerda do Nervión, não foi exclusivamente um solo a serviços de um balneário, mas sua população, até a década de 1980, trabalhava nas indústrias localizadas em Sestao e Baracaldo, que são vizinhos. Com a desindustrialização, as grandes siderurgias evadiram, e a população de operários emigrou para outros municípios de solo mais acessível.

Os municípios do Vale de Asúa (INE, 2018), Lujua, Sondica, Derio, Zamudio, Lezama e Larrabezúa comportam hoje polígonos industriais e novas atividades desse setor, incluindo serviços avançados à produção industrial. Derio comporta na atualidade polígonos industriais destinados à produção de ferramentas para jardinagem sofisticada, refrigeradores industriais, motores, concessionária da Bosch, com alta taxa de setores empresariais e serviços avançados. Por isso, tem renda per capita elevada, embora com valor da terra bem menor que Bilbao e outros municípios, o que justifica que venha atraindo população. Sondica e Zamudio comportam Parques Tecnológicos e industriais, e vem atraindo população. Lezama comporta polígonos industriais que produzem equipamentos, tais como calefação habitacional e elevadores, e serviços à produção industrial, o que explica porque ganhou população e renda per capita.

Os municípios da denominada Zona Mineira (INE, 2018), Valle de Trápaga, Abanto-Ciérvana, Ciérvana, Ortuella e Musques, que no passado se dedicaram à extração de minério de ferro, comportaram atividades industriais outrora importantes. Musques ainda mantém como principal atividade a refinaria de petróleo Petronor (Petróleo do Norte) e pequenas indústrias de transformação de madeira e metais, o que justifica sua relativa alta renda per capita e atração de população, com valor de solo bem mais acessível que outros locais. No que se refere a Ciérvana, apesar de estar classificado na comarca denominada Margem Esquerda, mantém-se por laços históricos vinculado administrativamente à Zona Mineira, e com a abertura do denominado Super Porto (BILBAO PORT, 2018), mantém relações

\footnotetext{
${ }^{2}$ A Lointek é uma empresa que atua nomercado internacional de engenharia, fornecimento, fabricação e serviços no setor de equipamentos para a indústria de refino de petróleo, química, petroquímica e energia, com energia renovável como energia solar térmica e hidrelétrica.
} 
econômicas com esta zona. Valle de Trápaga tem 16 polígonos industriais, siderometalúrgicos, material elétrico e mecânica, o que o faz ter renda per capita bem acima da média, com valor de solo bem mais acessível que outras localidades. O município de Abanto-Ciérvana se localiza próximo a Valle de Trápaga, com valor de solo bem abaixo deste, o que justifica ter ganho população em busca de moradia mais acessível e proximidade às oportunidades de trabalho em ambos.

Ciérvana contém grande parte das instalações portuárias do Super Porto (Abra Exterior), e os terrenos do Porto Autônomo de Bilbao lá se localizam, justificando a elevada renda per capita e o ganho de população. O município concentra ainda atividades pesqueiras, e é considerado um centro gastronômico e de lazer.

Arrankudiaga comporta um polígono industrial de Bakiola, especializado em soldaduras, montagem de rodas, distribuição de papelaria, explicitando assim a renda per capita acima da média e relativo ganho de população. Arrigorriaga atraiu população, e mantém valor do metro quadrado bem mais acessível que outras localidades. Tem atividades industriais e de comercialização diversificadas, relativas a alumínios, pinturas, cerâmicas, mecânica de precisão, comercialização de sucata industrial (metais), todas remanescentes dos anos 1950, período de auge da industrialização basca, o que o mantém ativo e com renda per capita elevada, e com valor de metro quadrado bem mais acessível que outros centros.

Basauri é um município industrializado, mas que perdeu várias de suas indústrias desde 1980. Mantém o valor da terra em padrões relativamente elevados, o que vem causando perda de população, desmotivada pelo custo de vida e retração das oportunidades de trabalho e emprego.

\section{Considerações finais}

O processo de regeneração urbana de Bilbao, desde há 20 anos apostou na especialização da cidade e sua região metropolitana em serviços e serviços avançados, como turismo, atividades culturais, atividades financeiras e imobiliárias, serviços a empresas, design, design de moda, e profissões liberais, que aposta hoje no último grande Projeto Urbano - o 
Parque Tecnológico de Zorrotzaurre - para aprofundar esta especialização produtiva. Para integrar-se à lógica europeia de financiamento de planos e programas, Bilbao se insere na pauta de planejamento regional e local que opera em rede, cujo alcance transcende as próprias fronteiras do Estado nacional, o que é exemplificado pela Rede InFocus, de que faz parte com outras cidades, pautadas pelo Documento RIS3. Ao integrar esta rede, e contendo outras, em escala regional e local, a cidade se insere em uma agenda competitiva e de disputa de recursos, para a realização de seu planejamento de enfoque regional e de Projetos Urbanos Estratégicos, de que é exemplo a ilha de Zorrotzaurre. A requalificação urbana atravessada pelo município nestas duas décadas, e os sistemas infraestruturais realizados - metrô, ferrovias, autoestradas, acarretaram, no entanto, uma sobrevalorização do preço da terra, gerando desequilíbrios em escala regional, e favorecendo oscilações de população residente e sua desconcentração no território de Bilbao Biscaia Next (Bilbao 45) o que justifica a proposição do plano. A proximidade de Zorrotzaurre e Zamudio, onde há um Parqu Tecnológico implementado desde o início dos anos 2000, é uma fonte de questionamento da eficácia do plano, que embora de discurso reticular e regional, investe no momento grande parte dos recursos ganhos ao FEDER no próprio município de Bilbao, contrariando se escopo de uma rede de redes.

A diáspora populacional regional, em busca de empregos em municípios com especializações produtivas geradoras de trabalho e renda, e moradia a menor custo, é um movimento de desconcentração em busca de reequilibração em um tecido bem conectado e servido por formas diversificadas de mobilidade, que em tese favorecem interconexões e associações nessa escala. As relações produtivas e logísticas dos municípios da Grande Bilbao e destes até mesmo com os municípios de outras províncias, a exemplo de Castro Urdiales, na Cantábria, evidenciam um território que sinaliza uma dependência sócioeconômica e sugerem uma rede policêntrica para Bilbao 45, conectando-o à capitalidade de Bilbao, e insinuando ações sinérgicas nesse âmbito. É possível notar, entretanto, a co-presença de lugares em declínio e outros plenos em concentração de riqueza, podendo-se ler também no território regional a requalificação urbana e a gentrificação (movimentos populacionais em função da valorização do preço da terra), gerando redes decorrentes da ação concreta dos processos sociais e produtivos. Evidenciam-se contradições entre pujança e declínio, concentração e dispersão populacional 
e produtiva, polos de pobreza e riqueza que ultrapassam os limites provinciais de Biscaia, propondo relações e conectividade com municípios de outras províncias fronteiriças, em Alava, Guipúscoa e Cantabria.

Bilbao Biscaia Next, ou Bilbao 45 é uma proposta de criação de redes produtivas e de serviços induzidas, com o pressuposto de que a região se fortaleça e alcance um equilíbrio entre empregos, equipamentos e serviços à população e à produção, explorando um potencial para estabelecer redes multiescalares. A reequilibração proposta pelo Plano em suas várias escalas enfrenta desafios de estabelecer relações interinstitucionais e alcançar um planejamento efetivamente coordenado e equânime, e a melhor distribuição de recursos disputados por cidades articuladas em redes, e de propor com clareza formas de concretização dos objetivos de equidade, convidando à continuidade das pesquisas que poderão avaliar sua concretização.

\section{Referências bibliográficas}

ABASCAL, Eunice Helena S. A regeneração urbana de Bilbao como processo dinâmico e polifônico. São Paulo FAU USP, 2004. Tese de Doutorado.

ABASCAL, Eunice Helena S. In: BALEIRAS, Rui Nuno. Casos de desenvolvimento regional. Universidade do Minho, Editora Princípia, 2011.

BALDISSERA, Adelina. “Pesquisa-ação: uma metodologia do 'conhecer' e do 'agir' coletivos". In: Sociedade em

Debate. Pelotas, 7(2), 2001. Pp. 5-25. Disponível em: http://revistas.ucpel.edu.br/index.php/rsd/article/viewFile/570/510. Acesso em 5 de janeiro de 2018.

BILBAO EKINTZA. Disponível em: http://www.bilbao.eus/BilbaoEkintza/es/index.html. Acesso em 28 de dezembro de 2017.

BILBAO PORT. Disponível em: https://www.bilbaoport.eus/en/. Acesso em 10 de bril de 2018.

BILBAO PORT. IN FOCUS. Presentation and current status of the project. Disponível em: http://www.bilbao.eus/cs/Satellite?pagename=LanEkintza/LKZ Noticia FA/LKZ PTNoticiaDetalle\&idPage=127

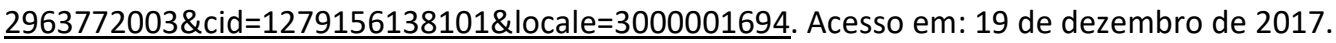

CASTELLS, Manuel. A sociedade em rede. São Paulo: Paz e Terra, 1999.

CENICACELAYA, Javier. "Bilbao y la urgencia de un urbanismo sostenible”, in: BORJA, Jordì; MUXI, Zaida. Urbanismo en el siglo XXI. Barcelona, ETSAB Escuela Técnica Superior de Barcelona, 2004.

CESCE. INFORMA. Gestión integral del riesgo comercial. Disponível em: https://www.informa.es/quienessomos/cesce.

CONTI, Sergio. Políticas espaciais europeias. in: DINIZ, Clelio Campolina (org). Políticas de desenvolvimento regional: desafios e perspectivas à luz das experiências da UE e Brasil. Brasíla UnB, 2007.

CONTI, Sergio. BILBAO OBSERVATORIO. Precios de la vivienda nueva y usada en Bilbao. Disponível em: http://www.bilbao.eus/cs/Satellite?blobcol=urldata\&blobheader=application\%2Fpdf\%3Bcharset\%3DUTF8\&bl obheadername1=ContentDisposition\%3A\&blobheadervalue1=attachment\%3Bfilename\%3DViviendalltrimestre 
2017.pdf\&blobkey=id\&blobnocache=true\&blobtable=MungoBlobs\&blobwhere $=1274180753399 \&$ ssbinary=tru e. Acesso em 15 de dezembro de 2017.

DETTORI, Stefano. O projecto urbano estratégico na revitalização da cidade. Perspectivas futuras para o desenvolvimento sustentável da cidade de Cascais. Dissertação de Mestrado. Lisboa IST Instituto Superior Técnico da Universidade de Lisboa, 2014.

EITB.eus. 'El gran proyecto de Bilbao para los próximos años es Zorrotzaurre'. Disponível em: http://www.eitb.eus/es/radio/radio-euskadi/programas/boulevard/detalle/4231194/el-gran-proyecto-bilbaoproximos-anos-es-zorrotzaurre/. Acesso em 12 de dezembro de 2017.

EGLER, Tamara Tania; TAVARES, Hermes de Magalhães (orgs). Política pública, rede social e território. Rio de Janeiro, Letra Capital, 2012.

EL CORREO. Playas de Vizcaya. Disponível em: http://www.elcorreo.com/planes/playas/bizkaia/. Acesso em 28 de dezembro de 2017.

EL MUNDO. Bajo la sombra del árbol de Guernica. Disponível em: file://C:/Users/EUNICE/Downloads/1304519579[1]\%20(5).html. Acesso em 20 de dezembro de 2017.

EL MUNDO. Castro Urdiales, un 'paraíso' inmobiliario cántabro para los vizcaínos. Disponível em: http://www.elmundo.es/elmundo/2008/02/19/suvivienda/1203416225.html. Acesso em 12 de dezembro de 2017.

EUSKADI.EUS. Toda la información, trámites y servicios del Gobierno Vasco. Disponível em: http://www.euskadi.eus/inicio/. Acesso em 10 de janeiro de 2018.

ESTENSORO, Miren; LARREA, Miren. Hacia un nuevo modelo de desarrollo territorial: el reto de reaprender formas de trabajo. Papeles del Pacto Industrial de Barcelona, $\mathrm{n}^{\circ}$. 2, dezembro de 2015. Disponível em: http://www.orkestra.deusto.es/es/investigacion/publicaciones/libros-informes/otras-colecciones/706-hacianuevo-modelo-desarrollo-territorial-reto-reaprender-formas-trabajo.

ESTENSORO, Miren; LARREA, Miren. Tapia acelera con 10 millones la estación del TAV en San Sebastián. Disponível em: http://www.elmundo.es/pais-vasco/2017/10/31/59f845e1468aebca598b461d.html. Acesso em 3 de janeiro de 2018.

ETXEBARRI Ayuntamiento. Economía. Disponível em: http://www.etxebarri.eus/es-ES/Paginas/default.aspx. Acesso em 228 de dezembro de 2017.

EUROPEAN COMISSION. European Structural and Investment Funds Regulations 2014-2020. Disponível em: http://ec.europa.eu/regional_policy/en/information/legislation/regulations/. Acesso em 30 de dezembro de 2017.

EUSTAT. Conoce la realidad estadística actual y la evolución histórica de tu município. Disponível em: http://www.eustat.eus/municipal/datos_estadisticos/bilbao.html. Acesso em dezembro de 2017.

EUSTAT. Directorio de atividades económicas y demografia empresarial. Disponível em: http://www.eustat.eus/banku/id_3452/indexLista.html. Acesso em: 22 de dezembro de 2017.

FORUM ALDUNDIA. DEPUTACIÓN FORAL DE VIZCAYA. “En qué consiste la revisión del PTP BM¿̇”, 2017 a. Disponível em: http://www.bizkaia.eus/hirigintza/lurraldekozatiegitasmoa/en que consiste.asp?idioma=CA\&Tem Codigo=10 130\&dpto biz=6\&codpath biz=6\%7C8366\%7C10128\%7C10130. Acesso em 8 de janeiro de 2018.

FORUM ALDUNDIA. DEPUTACIÓN FORAL DE VIZCAYA. “Parque Tecnológico de Zamudio”, 2017 b. Disponível em:

http://www.bizkaia.eus/Ogasuna/Gestion Fondos/ProyectosDestacados/zamudio.asp?Idioma=CA\&Tem Codi go=10510. Acesso em 8 de janeiro de 2018.

GORZ, Andre. O imaterial: Conhecimento, Valor e Capital. São Paulo Anna Blume, 2005.

GOVERNO BASCO. PLANES TERRITORIALES PARCIALES (P.T.P.). Disponível em: http://www.ingurumena.ejgv.euskadi.eus/r49-565/es/contenidos/informacion/ptp/es 1167/indice c.html. Acesso em 27 de dezembro de 2017. 
HARVEY, David. Cidades rebeldes: do direito a cidade à revolução urbana. São Paulo, Martins Fontes, 2013.

IDEE. Geoportal. Infraestructura de Datos Espaciales de España. Disponível em: http://www.idee.es/

INDOVINA, Francesco. O Espaço Público: Tópicos sobre a sua Mudança. Revista Cidades, Comunidades e Territórios, CET - ISCTE, Lisboa, 2002.

INE INSTITUTO NACIONAL DE ESTADÍSTICA. Disponível em: http://www.ine.es/dynt3/inebase/es/index.html?padre=517\&dh=1

LANBIDE TEKANIKA. ZORROTZAURRE: una isla para vivir, trabajar y disfrutar. Disponível em: http://www.zorrotzaurre.com/. Acesso em 13 de abril de 2018.

MASBOUNGI, Ariella; MANGIN, David. Agir sur les grands territoires. Paris, Éditions Le Moniteur, 2009.

MUCHOCASTRO. El Ayuntamiento estima entre 20.000 y 30.000 el número de "ciudadanos invisibles" de Castro Urdiales. Disponível em: C: \Users\EUNICE\Downloads \88166-el-ayuntamiento-estima-en-20-000-y-30000-el-numero-de-ciudadanos-invisibles-de-castro-urdiales[1] (2). Acesso em 17 de dezembro de 2017.

NOVICKI, Alicia. Proyectos urbanos y otras histórias. Buenos Aires, Nobukko; Sociedad Central de Arquitectos, 2012.

PREFEITURA DE BILBAO. Zorrotzaurre, Isla Creativa. Disponível em: http://www.zorrotzaurre.com/islacreativa/. Acesso em 24 de janeiro de 2018.

ORKESTRA. INSTITUTO VASCO DE COMPETITIVIDAD. Orkestra-UD en Bibao Next Lab. Bilbao, 2014. Disponível em: http://www.orkestra.deusto.es/es/investigacion/proyectos-investigacion/75-bilbao-nextlab. Acesso em 23 de dezembro de 2017.

ORKESTRA. INSTITUTO VASCO DE COMPETITIVIDAD. Rasgos estructurales y pautas de comportamiento empresariales en la estratégia de cooperación de empresas bilbaínas. Bilbao, 2014.

PREFEITURA DE CASTRO URDIALES. Disponível em: www.castro-urdiales.net. Acesso em 12 de abril de 2018.

SABATÉ BEL, Joaquín. Paisajes Culturales. El património básico para un nuevo modelo de desarrollo. In: Urban 9. Disponível em: http://www.cidadeimaginaria.org/pc/Patrimrecurso.pdf. Acesso em 13 de dezembro de 2017.

SASSEN, Saskia. Cities and City Regions in Today's Global Age. (2007). Disponível em: https://Isecities.net/media/objects/articles/cities-and-city-regions-in-todays-global-age/en-gb/. Acesso em 1 de abril de 2018.

SECCHI, Bernardo. Primeira Lição de Urbanismo. São Paulo, Ed. Perspectiva, 2006.

SER CANTABRIA. El precio de la vivienda cae un 2,5 por ciento en un año. Disponível em: http://cadenaser.com/emisora/2017/11/09/ser castro urdiales/1510226881 671307.html. Acesso em 9 de dezembro de 2017.

SMITH, Neil. Gentrification of the City (edited with Peter Williams). George, Allen and Unwin, London, 1996.

SMITH, Neil. Desenvolvimento Desigual: natureza, capital e a produção do espaço. Trad. Eduardo de Almeida Navarro. Rio de Janeiro: Bertrand Brasil,1988.

SOJA, Edward. Geografias pós-modernas. A reafirmação do espaço na teoria social crítica. Rio de Janeiro: Jorge Zahar Editor, 1993.

UIA URBAN INNOVATE ACTIONS. Bilbao receives 4.5 million from Europe for the creation of an innovation centre in Zorrotzaurre. 13 de Outubro de 2016. Disponível em: http://www.uia-initiative.eu/en/bilbaoreceives-45-million-europe-creation-innovation-centre-zorrotzaurre. Acesso em 27 de dezembro de 2017.

URBACT- Urbact em Portugal. A dimensão urbana da especialização inteligente: construção de uma ponte bidirecional. Disponível em: http://urbact.eu/dimens\%C3\%A3o-urbana-da-especializa\%C3\%A7\%C3\%A3ointeligente-constru\%C3\%A7\%C3\%A3o-de-uma-ponte-bidirecional. Acesso em: 3 de abril de 2018.

URBACT- Urbact em Portugal I. Disponível em: http://urbact.eu/urbact-em-portugal. Acesso em 2 de janeiro de 3018. 
URBACT- Urbact em Portugal. The urban dimension of smart specialisation: building a two-way bridge. Disponível em: http://urbact.eu/urban-dimension-smart-specialisation-building-two-way-bridge. Acesso: 23 de dezembro de 2018.

VEGARA, Alfonso; RIVAS, Juan Luis de la. Territorios Inteligentes. . In: Ambienta, no. 89, pp. 34-58. Madrid, 2004. 